\title{
Hydrogen evolution via noble metals based photocatalysts:
}

\section{A review}

\author{
Asieh Akhoondi ${ }^{a, *}$, Ankush Sharma ${ }^{b}$, Dinesh Pathak ${ }^{\text {b }}$, Mohammad Yusuf ${ }^{\text {c,d }}$, \\ Taye B. Demissie ${ }^{\text {e }}$, Rui-tang Guo ${ }^{\text {f,g }}$, Adnan Ali ${ }^{\text {h }}$ \\ ${ }^{a}$ Department of Chemical Engineering, Arak Branch, Islamic Azad University, Arak, Iran \\ ${ }^{b}$ School of Physics and Materials Science, Shoolini University of Biotechnology and Management Sciences, Solan 173212, India \\ ${ }^{c}$ Department of Chemical Engineering, Universiti Teknologi PETRONAS, Bandar Seri Iskandar, 32610, Perak, Malaysia \\ ${ }^{d}$ Centre of Contamination Control and Utilization (CenCoU), Universiti Teknologi PETRONAS, Bandar Seri Iskandar, 32610, Perak, Malaysia \\ ${ }^{e}$ Department of Chemistry, University of Botswana, Notwane Rd, P/bag UB 00704, Gaborone, Botswana \\ ${ }^{f}$ College of Energy Source and Mechanical Engineering, Shanghai University of Electric Power, Shanghai 200090, People's Republic of China \\ ${ }^{g}$ Shanghai Engineering Research Center of Power Generation Environment Protection, Shanghai 200090, People's Republic of China \\ ${ }^{h}$ Luxi Polymetal Co. Ltd., Abuja, Nigeria
}

\section{A B S T R A C T}

In recent decades, the use of photocatalysts in the evolution of hydrogen $\left(\mathrm{H}_{2}\right)$ has received much attention. However, the use of the well-known titanium oxide and other photocatalysts as a base for noble metals is limited due to their major weakness in electron-hole pair separation. The use of cocatalysts can be a good way to overcome this problem and provide better performance for the evolution of hydrogen. In this review, suitable high-efficiency cocatalysts for solar hydrogen production have been thoroughly reviewed. New strategies and solutions were examined in terms of increasing the recombination of charge carriers, designing reactive sites, and enhancing the wavelengths of light absorption. Several new types of cocatalysts based on semiconductors in noble groups and dual metals have been evaluated. It is expected that these photocatalysts will be able to reduce the activation energy of reaction and charge separation. In this regard, the existing views and challenges in the field of photocatalysts are presented. The characteristics of monoatomic photocatalysts are reviewed in this manuscript and the latest advances in this field are summarized. Further, the future trends and upcoming research are also briefly discussed. Finally, this review presents noble metal-based photocatalysts for providing suitable photocatalysts on a larger scale and improving their applicability.

C 2021 The Authors. Published by Synsint Research Group.

\section{Introduction}

The challenge facing all countries in the world today is the reduction of fossil fuels [1]. The growing need for energy, the increasing destructive environmental impacts, climate change, greenhouse gases emissions and socio-economic development underscore the importance of using
KEYWORDS

Photocatalyst
$\mathrm{H}_{2}$ production
Semiconductor
Visible light
Bandgap
Synthesis

Photocatalyst

Semiconductor

Visible light

Synthesis renewable energy sources [2]. Therefore, researchers are looking for a serious solution to reduce fossil fuel consumption and replace it with solar energy [3]. In the 1970s, for the first time, hydrogen production from the photocatalytic water splitting was successfully accomplished by Fujishima and Honda [4]. Solar power is used as a free and

* Corresponding author. E-mail address: asieh.akhoondi@gmail.com (A. Akhoondi)

Received 5 November 2021; Received in revised form 29 December 2021; Accepted 29 December 2021.

Peer review under responsibility of Synsint Research Group. This is an open access article under the CC BY license (https://creativecommons.org/licenses/by/4.0/). https://doi.org/10.53063/synsint.2021.1468 


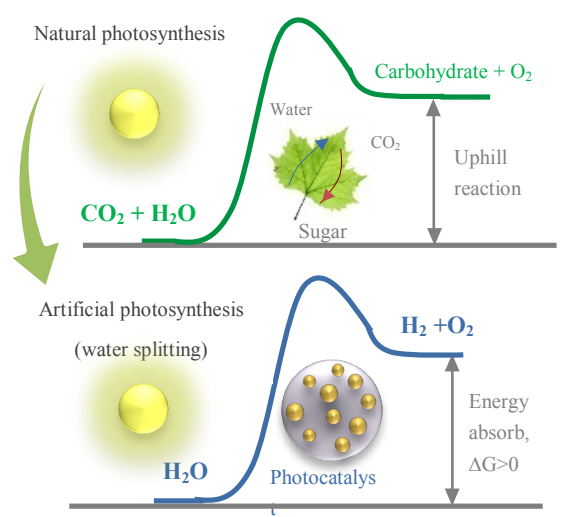

Fig. 1. Photocatalytic splitting of water inspired by natural photosynthesis.

available source in other technologies such as wastewater treatment [5], photocatalysis and photovoltaics [6], $\mathrm{N}_{2}$ fixation [7], prevent $\mathrm{CO}_{2}$ emissions [8], hydrogenation of nitro compounds [9], removal of air pollutants [10], the production of hydrocarbon fuels [11] and other hydrocarbon compounds [12]. Information gaps and access to raw materials are barriers to the sustainable use of renewable resources. Solar fuel production as an economical process must be prepared from plentiful and cheap feedstocks such as $\mathrm{H}_{2} \mathrm{O}$ and $\mathrm{CO}_{2}$.

The process of natural photosynthesis has been the basic idea that oxygen can be produced through solar energy, as depicted in Fig. 1. With this strategy, water splitting experiments through artificial photosynthesis were performed at the end of the last century. Solar energy as a substitute for electricity is a new and promising strategy for the water-splitting reaction and hydrogen evolution [13]. According to the origin, $\mathrm{H}_{2}$ is color-coded; yellow $\mathrm{H}_{2}$ is generated through electrolysis by solar energy. Water splitting using photocatalytic technology is one of the hydrogen production methods from renewable sources [14]. According to Eq. 1, hydrogen is produced from water during the photo electrolysis reaction [15]:

$\mathrm{H}_{2} \mathrm{O} \rightarrow 1 / 2 \mathrm{O}_{2(\mathrm{~g})}+\mathrm{H}_{2(\mathrm{~g})} ; \Delta \mathrm{G}=+237 \mathrm{~kJ} \mathrm{~mol}^{-1}$

Hydrogen can also be produced by reforming organic matter derived from renewable biomass [16] [17]. It should be noted that there are other ways to produce hydrogen using solar energy [18]. In addition to the photocatalytic method, photoelectrochemical water splitting [19] and electrolysis techniques [20] have also been used to produce hydrogen. Photocatalytic hydrogen evolution is preferred, due to the corrosive nature of water electrolysis. Photocatalysts are one of the substrates for many chemical reactions that work through the visible spectrum of sunlight [21]. Therefore, in recent years, the technology of photocatalysts has grown exponentially, which of course is associated with several challenges. Solving these challenges depends on understanding photocatalysts and their molecular behavior. The most widely used known photocatalyst is titanium oxide $\left(\mathrm{TiO}_{2}\right)$, which has been studied in various researches and its behavior has been evaluated. Despite the advantages of this photocatalyst, such as light stability, high activity, non-toxicity, environmentally friendly, and low cost, it has disadvantages that limit its application. Wide bandgap energy, inefficient use of visible light and low quantum performance of $\mathrm{TiO}_{2}$ led to extensive research on the other photocatalysts. The energy bandgap in $\mathrm{TiO}_{2}$ is activated only under ultraviolet light, which includes a limited range of sunlight. Therefore, the goal is to find an alternative photocatalyst to achieve the highest efficiency in the best conditions.

Understanding the basic principles of photocatalyst performance helps solve problems and challenges and leads to the development of research to implement hydrogen production on a larger scale. Fig. 2 shows a photocatalytic reaction in three steps, including unit cell, bulk phase, and surface phase. In this figure, $\mathrm{CB}$ and VB represent the conduction band and the valence band, respectively. Factors such as particle size, surface are, and calcination temperature affect the photocatalytic activity of photocatalyst. In addition to $\mathrm{TiO}_{2}$, other semiconductors such as $\mathrm{MoS}_{2}$ [22], $\mathrm{BiPO}_{4}$ [23], $\mathrm{BiVO}_{4}$ [24], $\mathrm{Cu}_{2} \mathrm{O}$ [25], $\mathrm{CdS}$ [26], $\mathrm{WO}_{3}$ [27], $\mathrm{ZnO}$ [28], $\mathrm{CoS}_{2}$ [29], $\mathrm{WS}_{2}$ [30] and $\mathrm{Co}_{3}\left(\mathrm{PO}_{4}\right)_{2}$ [31] have been used for hydrogen evolution. Different composites that were constructed in several methods have also been used to achieve high optical efficiency [32]. Composites based on g$\mathrm{C}_{3} \mathrm{~N}_{4}$ [33], CNTs [34], N-doped carbon [35], ZIF [36], $\mathrm{Ti}_{4} \mathrm{O}_{7}$ [37], reduced graphene oxide (RGO) [38] and activated carbon [39] have also been investigated in recent research. Through the deposition of cocatalyst on the photocatalyst surface, the activation energy of the reaction is reduced and the process efficiency is increased due to the acceleration of the reaction. In photocatalytic processes,

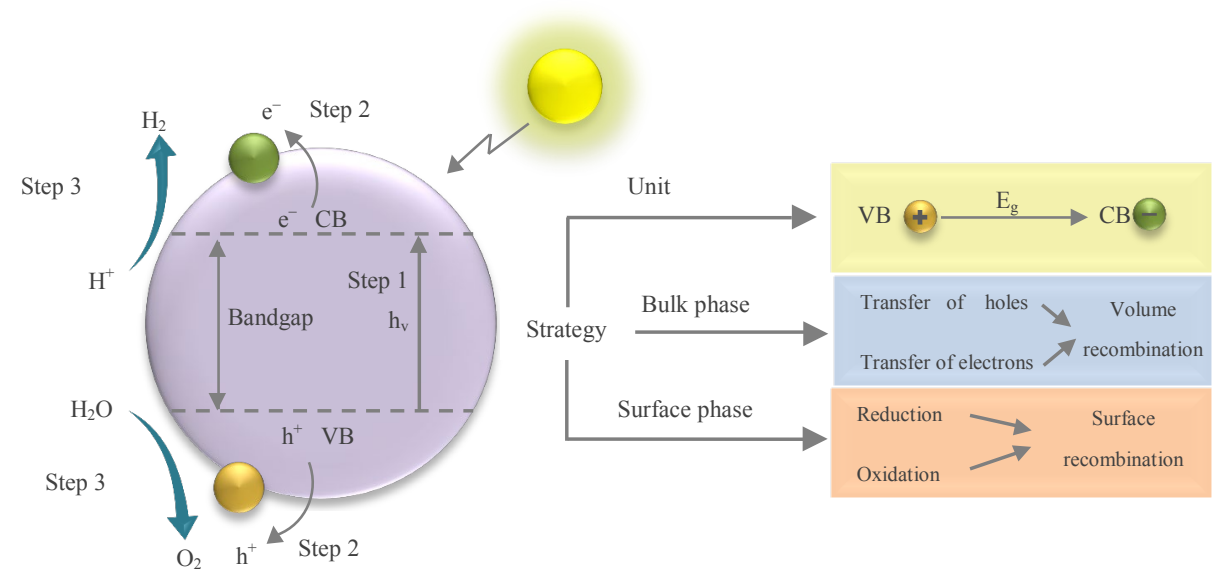

Fig. 2. Schematic representation of fundamentals photocatalytic reactions in heterogeneous semiconductor. 
semiconductors are often used to absorb photons and produce $\mathrm{e}^{-} / \mathrm{h}^{+}$ pairs in order to increase the rate of redox reactions.

The cocatalysts are divided into two main groups: oxidizing $\left(\mathrm{RhO}_{\mathrm{x}}\right.$, $\mathrm{RuO}_{2}, \mathrm{IrO}_{2}, \mathrm{CoO}_{\mathrm{x}}$, etc) and reducing ( $\mathrm{Ru}, \mathrm{Rh}, \mathrm{Pd}, \mathrm{Pt}, \mathrm{Au}$, etc). Extensive advances have been made in the field of transition metal carbide (TMCs) [40], transition metal nitride (TMNs) [41], metalorganic framework photocatalysts (MOFs) [42], transient metal sulfides (TMSs), intermediate metal oxides (TMOs) [43], and intermediate metal dicalcogenides [44]. Covalent organic frameworks (COFs), as porous polymers, are a promising new category with high flexibility [45]. This group of new photocatalysts could pave the way for the efficient production of commercial hydrogen.

Kavitha et al. have reviewed noble metal deposited graphitic carbon nitride (GCN) for various photocatalytic applications [46]. Recently, Passi and Pal have summarized modification strategies including noble metal doping on calcium titanate $\left(\mathrm{CaTiO}_{3}\right)$ and production of green currency energy [47]. The latest development on $\mathrm{SnO}_{2}$-based photocatalysts such as dye-sensitized and noble metal modified $\mathrm{SnO}_{2}$ has been investigated by Sun et al [48]. In recent years, new semiconductor photocatalysts such as indium vanadate $\left(\mathrm{InVO}_{4}\right)$ coupling with noble metals have been considered for energy/environmental applications, which Young et al. have given an overview on the challenges and future researches [49]. For enhanced photocatalytic hydrogen $\left(\mathrm{H}_{2}\right)$ production the latest signs of progress in the design and construction of bimetallic cocatalysts have also been reported by Liu et al. [50]. Thus, noble metals as a large group of cocatalysts have attracted considerable attention for the catalytic evolution of $\mathrm{H}_{2}$.

The most important principles in photocatalytic water splitting process are sunlight exposure consideration, the reaction mechanism in the optimized design reactor, and economic estimation for scale-up. Accurate knowledge of solar radiation is very important because it is used to evaluate the $\mathrm{H}_{2}$ production. Solar irradiation reports can be collected to evaluate solar fuel production with field measurement tools or through solar radiation databases. The sun's rays are collected and transmitted to the photocatalyst surface in a photoactor. So far, membrane reactors [51], surface uniform concentrator [52], compound parabolic concentrator [53], column reactors, and parabolic trough collector [54] have been considered to perform the water-splitting reaction [55]. Membrane photocatalytic reactors minimize the harmful effects of the environment and are cost-effective. Another advantage of these reactors is that they react and separate materials in one step, which reduces the complexity of the process and leads to further cost reductions. An important parameter in reactor design is the possibility of maximum solar radiation entering so that photocatalysts can absorb more photons and supply the necessary electrons. Many photocatalysts are known to capture solar photons, which accelerate their transfer into the photocatalyst. So far, several laboratory-scale photoreactors have been developed to produce hydrogen by absorbing sunlight, but there are still challenges in achieving production on an industrial scale.

In this review, promising approaches for hydrogen production with noble metal photocatalysts have been considered. Noble metals are some of the intermediate metals in periods 4,5 and 6 in the periodic table that have high chemical resistance even at high temperatures and are used in many chemical reactions due to their catalytic properties. Generally, noble metals including platinum, palladium, gold, ruthenium, rhodium, silver, etc. can assist as reduction cocatalysts for the water-splitting reaction. Although noble metals have a small amount in nature, but their consumption is also low so that the presence of these elements in the earth's crust is sufficient. In many studies, noble metals have been studied single-atom, in layers, oxides and sulfides to produce hydrogen and some papers have reviewed the effect of these metals on a special base. This study summarizes the advantages and functions of these metals in a comprehensive way such as activity, performance and stability considering all kind of substrates. Logical strategies such as doping, composite structure, color sensitization, defect engineering, and others have been used to increase the activity of photocatalysts. The use of metal atoms in a cocatalyst consisting of a solid substrate coated with a metal in heterogeneous reactions is a new method that has also been used in the evolution of hydrogen. It is noteworthy that in the evolution of hydrogen, aqueous solutions are also examined. Therefore, the role of impurities and reagents in the amount of light absorption and process efficiency is undeniable.

\section{Fundamentals of photocatalytic water splitting}

Many advances have been made in the photocatalytic production of $\mathrm{H}_{2}$, which overlaps with environmental standards and has relatively low production costs, so it is expanding as a reliable technology [56]. Therefore, understanding the basic concepts of the water-splitting reaction based heterogeneous catalyst is essential to optimize the process and increase its efficiency. As shown in Fig. 3, the water splitting reaction under solar energy using a semiconductor directly results in the production of hydrogen and oxygen [57]. $\mathrm{H}_{2} \mathrm{O}$ splitting is actually performed with the $\mathrm{TiO}_{2}$-based semiconductors to provide sufficient reaction potential. Water molecules are oxidized to $\mathrm{h}^{+}$to generate oxygen, while protons $\left(\mathrm{H}^{+}\right)$are reduced by $\mathrm{e}^{-}$to produce hydrogen. In semiconductors as heterogeneous photocatalysts, there is an energy gap between electronic states, known as a bandgap, which varies in different solids [13]. The electron in its normal state of energy, called the valence band, is excited by receiving enough energy such as sunlight, and is placed in the conduction band, so positive hole $\left(\mathrm{h}^{+}\right)$is produced in valence band [16]. Electrons and holes as charged species at the photocatalytic surface can participate in oxidation/reduction reactions, which are summarized in Fig. 2. According to Eq. 2, hydrogen is generated by $\mathrm{H}^{+}$and $\mathrm{e}^{-}$, and water reacts with hole ${ }^{+}$to produce oxygen in Eq. 3 by 2:1 stoichiometry ratio.

$2 \mathrm{H}^{+}+2 \mathrm{e}^{-} \rightarrow \mathrm{H}_{2}$

$\mathrm{H}_{2} \mathrm{O}+2 \mathrm{~h}^{+} \rightarrow 1 / 2 \mathrm{O}_{2}+2 \mathrm{H}^{+}$

Therefore, the general reaction will be in the form of Eq. 4:

$\mathrm{H}_{2} \mathrm{O}+2\left(\mathrm{~h}^{+}+\mathrm{e}^{-}\right) \rightarrow \mathrm{H}_{2}+1 / 2 \mathrm{O}_{2}$

As mentioned earlier, hydrogen can also be produced by biomass decomposition, i.e. $\mathrm{H}_{2} \mathrm{O}$ reduction sacrificing half-reaction, which of course carbon dioxide is one of the by-products of the reaction [58]. As shown in Fig. 3, this process is also possible under solar energy by a semiconductor in ambient conditions. The semiconductor used in this reaction must have the potential to convert $\mathrm{H}^{+}$to $\mathrm{H}_{2}$ and reduce water. The water-splitting reaction is thermodynamically limited by the bandgap energy and potential of the valence and conduction bands [13]. Therefore, the consumable photocatalyst must have the necessary precondition, i.e. having conduction band energy greater than the $\mathrm{E}_{\mathrm{CB}}$ and a band energy capacity smaller than the $\mathrm{E}_{\mathrm{VB}}$ [59]. The choice of 


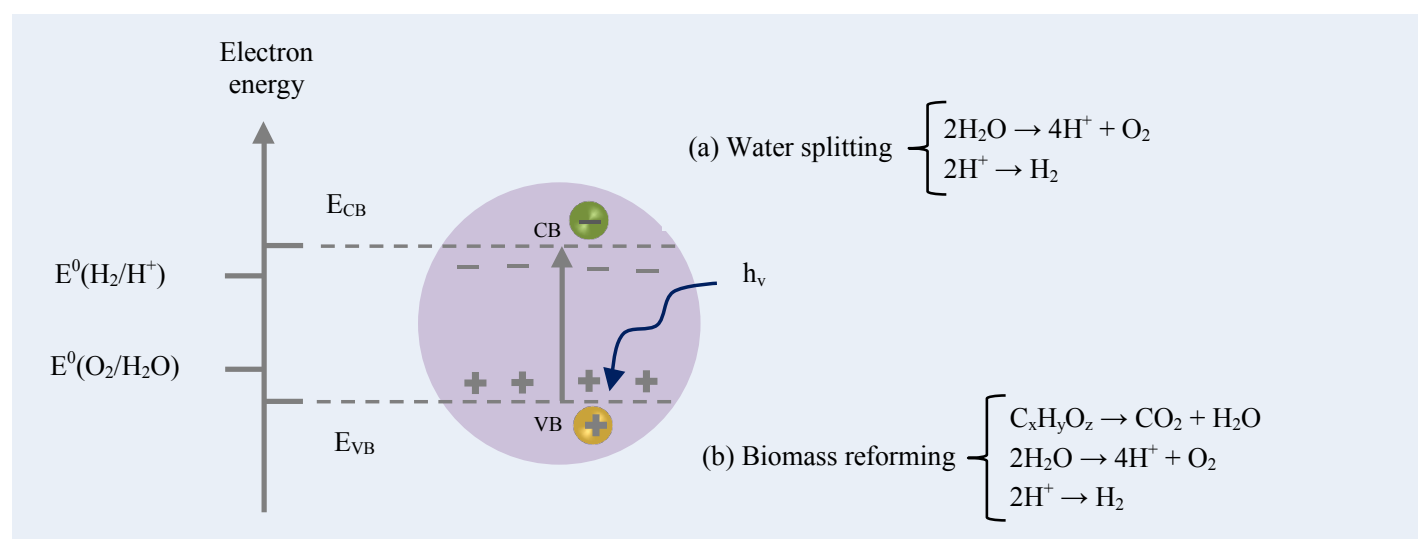

Fig. 3. Photocatalytic water splitting and biomass reforming.

photocatalyst and its design is also more limited thermodynamically due to the bandgap energy ( $>2 \mathrm{eV})[60]$. Hence, by substituting noble metals on the surface of semiconductors as stimuli, it is tried to accelerate the reactions rate and make it easier to separate the $\mathrm{e}^{-} / \mathrm{h}^{+}$pair to increase the efficiency of the process. The hydrogen evolution is entirely dependent on the performance of the cocatalytic system [59]. As mentioned above, the cocatalyst must have the necessary conditions to supply the reaction energy. In total, the photocatalytic process of hydrogen evolution consists of some basic stages: 1) absorption of light, 2) dissociation and transfer of photoproduced electron/hole pairs, and 3) oxidation and reduction surface reactions [16]. So the main challenges in solar to $\mathrm{H}_{2}$ energy conversion lie in these three steps [61]. The receive radiant energy $\left(h_{v}\right)$ the semiconductor must be larger than the bandgap energy $\left(E_{g}\right)$ to be capable to excite the $\mathrm{e}^{-}$and create $\mathrm{h}^{+}$ [62]. The prerequisites for photocatalytic reactions are the presence of an empty conduction band and an occupied valence band, which can produce electron/hole pairs by receiving photons. By stimulating electrons or photons in the conduction band $(\mathrm{CB})$, a surface plasmon is produced on the semiconductor [63]. In nanoscience, plasmonic properties have set a new pathway in the synthesis of photocatalysts [64]. To convert solar energy to hydrogen, a pair of light-generating electron/hole must be used to affect the redox reaction efficiently. Therefore, the combination of electron/hole pairs should be avoided, which is one of the challenges of this process. Control of photocatalytic properties by various methods such as surface protection layer deposition, co-catalyst loading and configuration design can be effective in this field.

The electron donors known as sacrifice agents could produce holes and facilitate charge/carrier separation [65]. Photocatalytic efficiency could improve by descending the recombination of excited $\mathrm{e}^{-} / \mathrm{h}^{+}$pairs via the addition of sacrificial reagents [66]. Although this is not a real watersplitting reaction, hydrogen production with sacrificial reagents is a potential and efficient method. Various sacrificial reagents have been introduced by researchers that can be prepared from waste or biomass [67].

The equilibrium of the water-splitting reaction is affected by the solution acidity. By adjusting the $\mathrm{pH}$ of the reaction solution, the migration of charge carriers can be limited [68]. Depending on the type of semiconductor, different $\mathrm{pH}$ ranges are used in each photocatalytic system.

\section{Problems of UV-light absorption}

Photon absorption is the first stage in the photocatalytic reactions that enhances with increasing light absorption [69]. Part of the incident radiation that hits the surface is absorbed and the other part is reflected. Concave surfaces, with multidimensional scattering, reflect light to their surface and lead to the absorption of the full spectrum. The ability of semiconductors to achieve the reaction of splitting water with solar energy depends on their photoactivity and substrate [70]. As shown in Fig. 4, semiconductors have different bandgaps, some of which are suitable for hydrogen production depending on the VB and CB levels. The inherent band frame controls the properties of photocatalyst such as electronic transition energy level. By modifying the band structure, charge/carrier mobility can be improved and the photocatalyst potential for redox reactions increased. Because many semiconductors are only capable of performing the desired reactions in the visible light range, they combine with metals and other materials to obtain a cocatalyst with the desired properties. The photo efficiency of semiconductors is also limited by charge/carrier recombination, so they must be slowed down by special techniques [71].

Various techniques have been proposed to enhance the response of light absorption in semiconductors. Since the number of active light site plays a main role in preventing recombination of charge carrier, the main strategy is focuses on this factor [13]. By reducing semiconductor size on a nanoscale, the surface area greatly increases, so designing nanoscale photocatalysts is a good method to improve their performance. Furthermore, the presence of pores on the photocatalyst surface is required to absorb the reactants. Therefore, by modifying the structure and morphology of the surface, the diffusion of molecules and ions can be increased for further collisions [72]. Also, the noble metalbased catalysts have positive effects in better absorption of UV light. In addition, the separation of charges can be facilitated by the doping of noble metals particles such as platinum, gold, silver, palladium, etc. on the surface of semiconductors.

\section{The roles of cocatalysts}

So far, a lot of research has been done on designing a suitable photocatalyst based on semiconductors [73]. In general co-catalysts have four primary positive roles in photocatalysis kinetics: 1) light- 


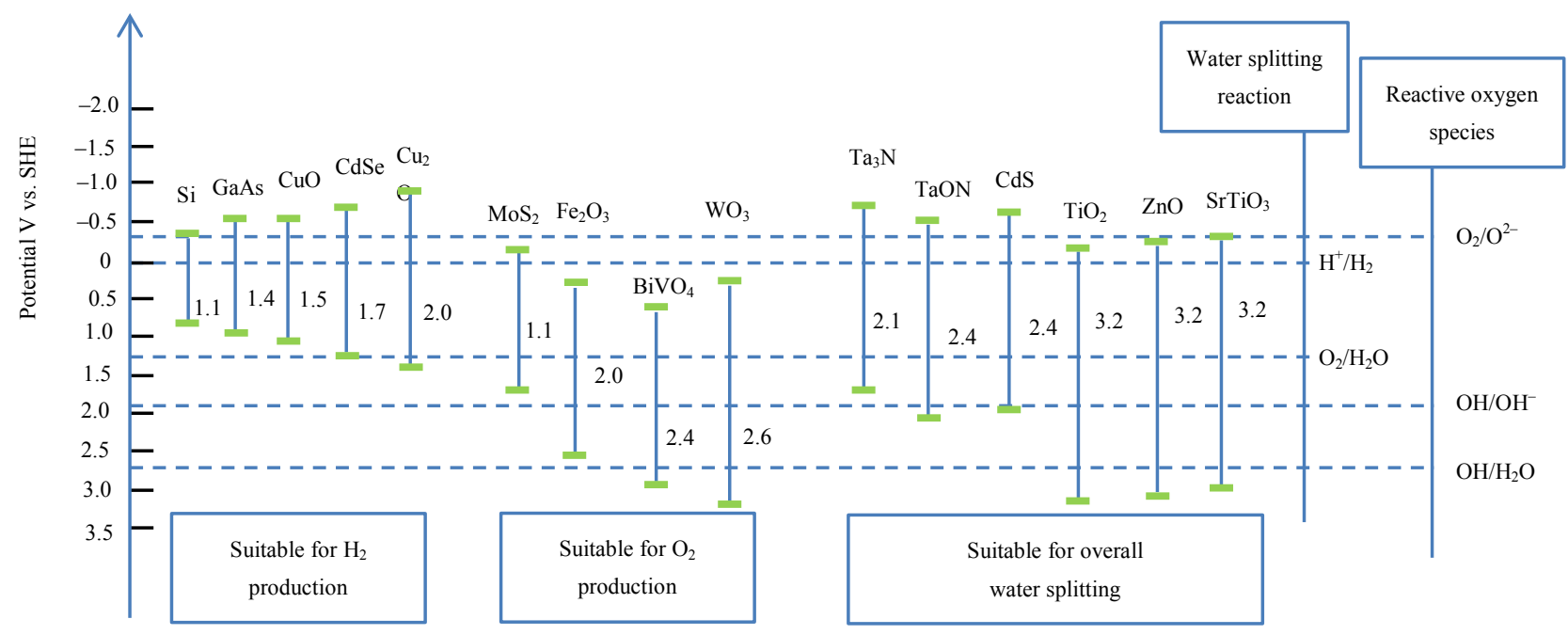

Fig. 4. Bandgap energy and band position of several photocatalysts used in $\mathrm{H}_{2}$ evolution.

harvesting center, 2) act as the interface with the semiconductor to effectively catch charge carrier and encourage electron-hole pair separation, 3) they also act as efficient active sites for supplying trapped charges to redox reaction, 4) they also take effect as an alternative reaction site for supporting the photocorrosion of semiconductor. Depending on the type of surface reaction, cocatalysts have different functions, some trapping electrons only in reduction reactions, some participating in oxidation reactions using holes, and others in redox reactions. So, the structures proposed for cocatalysts can be divided into several categories: 1) oxidation photocatalyst, 2) reduction photocatalyst, 3) redox photocatalyst, 4) plasmonic photosensitizers or metals photocatalyst and 5) plasmonic metal or photosensitizer without the bridge of a semiconductor. In addition to the water-splitting reaction, these groups are also used in the conversion of carbon dioxide [74]. To enhance the use of solar energy, the rational drawing of architecture compound combined with nanoscience is an attractive pathway that transforms the properties of photocatalysts such as plasmonic features. It is not necessary to photo stimulate semiconductors loaded with cocatalysts [75]. Plasmonic particles have the ability to couple electron density with beam radiation, while pure metals have limitations. Therefore, by combining photocatalysts and plasmonic metals, $\mathrm{e}^{-} / \mathrm{h}^{+}$can be injected into the $\mathrm{CB}$ and the VB, respectively [76]. In this way, enough electrons and holes are provided to perform surface reactions [77]. It is rare for plasmonic metal without semiconductors to be used to form a hybrid structure in which electrons/holes are induced directly into the cocatalyst and participate in redox reactions.

Generally, noble metals such as palladium, platinum and rhodium, noble metal sulfides (e.g. $\mathrm{As}_{2} \mathrm{~S}, \mathrm{PdS}$ ), noble metal oxides (e.g. $\mathrm{IrO}_{\mathrm{x}}, \mathrm{RuO}_{\mathrm{x}}$ ), and noble metal phosphates (e.g. $\mathrm{AgPO}_{4}$ ) can be utilized as cocatalysts in the water-splitting reaction. Various forms have been used to integrate these cocatalysts into photocatalysts. In these cocatalysts, the charge carriers transfer from the valence and conduction bands to the hybrid photocatalyst [46]. The synergistic effects of the hybrid photocatalyst created with the new architecture enable efficient transfer of charge carriers and prevent $\mathrm{e}^{-} / \mathrm{h}^{+}$recombination. Fig. 5 shows the position of noble metals in the periodic table.

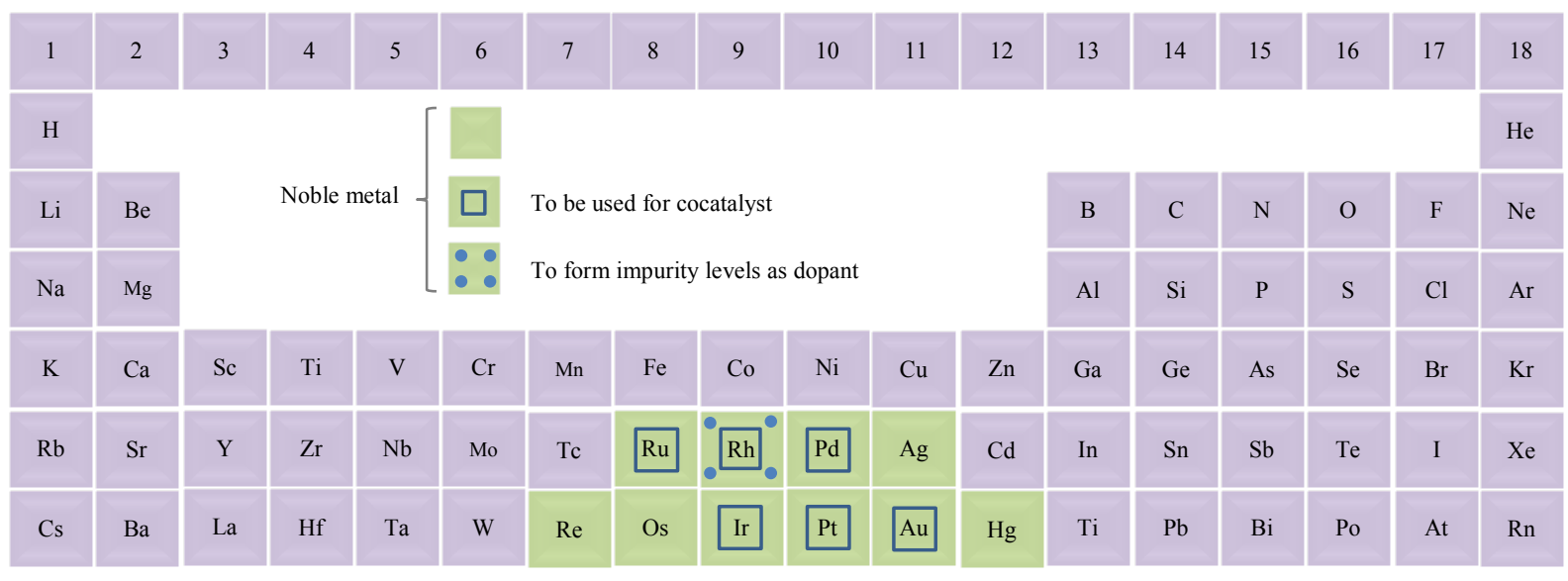

Fig. 5. Noble metals in periodic table. 


\section{Strategies to improve photocatalytic performance}

The big challenge in maximizing sunlight usage is finding a photocatalyst that can absorb a extensive range of light from infrared to visible and ultraviolet region [78], which makes up 52\% of the solar spectrum [79]. The ability of light absorption in photocatalysts is measured by the absorption coefficient and Lambert's law-beer [80]. The light that hits the surface is directly reflected. If the surface is uneven, light reflection can be scattered to increase light absorption. Therefore, modifying the surface structure of photocatalysts can be a good way to increase light scattering. Nanoscience and the use of single atoms have been useful in this regard [81]. This obliges researchers to focus on nanotechnology and even isolated atoms. In general, basic design at the atomic level is required for efficient charge migration. The types of noble metals used in photocatalytic systems in the production of hydrogen by splitting water are discussed below.

\subsection{Single noble metal}

The single atomic catalyst technique is a unique strategy in the photocatalytic production of hydrogen that has many advantages. By choosing the proper metal, the activity of the catalyst can be increased, while at the same time the selectivity of the desired reactions is increased and the process costs are reduced. Scattering of metal atoms based on a semiconductor as a support can increase production speed at the nanoscale and drastically reduce costs. One of the first metals used was $\mathrm{Ru}$ and $\mathrm{Pt}$ to reduce water, and nanoscale $\mathrm{RuO}_{2}$ for water oxidation [81]. Of all the noble metals, platinum is the most widely used metal in the field of the converting solar energy into hydrogen [82].

The methods used so far to increase the absorption of solar radiation have yielded promising and attractive results. Application of dye sensitizers and metal doping on semiconductor base are among these methods. These techniques are utilized to expand the range of visible light absorption and regulate the bandgap of semiconductors. Doping of intermediate metal ions creates surface close to $\mathrm{CB}$ within the bandgap to receive electrons. Adding metallic ions also enhances the mobility of charge carriers [83]. However, the dopant can itself become electron/hole recombination centers [84]. Elemental Au is a good example of increasing the light absorption under solar spectrum that is doped on $\mathrm{TiO}_{2}$ [85]. Plasmon resonance in this photocatalyst has a good performance in water splitting and hydrogen production. The rate of $\mathrm{H}_{2}$ production is correlated with plasmon resonance, which has been attributed to the key role of gold in $\mathrm{Au} / \mathrm{TiO}_{2}$ nanoparticles (NPs). Methanol acts as a very effective sacrificial agent because it has no C$\mathrm{C}$ bond and does not produce undesirable carbon products and reduces photocatalytic deposition [86]. Porous semiconductors that have a nanoscale structure can provide an extensive specific surface area with many energetic sites and therefore increase the activity of photocatalyst, because in such structures it is associated with increased sunlight absorption. Gold nanoparticles can absorb photoelectrons produced nearby, so they act as electron sinks effectively and protons reducer. The $\mathrm{g}-\mathrm{C}_{3} \mathrm{~N}_{4}$ Fermi level is increased by the addition of TEOA (triethanolamine) and subsequently the charge transfer pathway is modified.

Strontium titanate-based materials are promising new materials used to produce hydrogen under visible light [87]. $\mathrm{SrTiO}_{3}$ has many advantages such as low cost and photochemical resistance [88]. Rh doped $\mathrm{SrTiO}_{3}$ has been investigated for hydrogen evolution [89]. The polymerizable complex method has been used to synthesis of $\mathrm{SrTiO}_{3}$ and the optimum temperature has been found for calcination. The sample activity is dependent on the preparation method, for example, hydrothermal method or solid state reaction has less activity. $\mathrm{Rh}: \mathrm{SrTiO}_{3}$. Lanthanum doping of $\mathrm{Rh}: \mathrm{SrTiO}_{3}$ in two-step solid-state reaction produces core/shell structured photocatalyst and suppresses inactive $\mathrm{Rh}^{4+}$ species [90] as an efficient method for improve photocatalytic water splitting process [91].

The photo-deposition method has been used to platinized for the $\mathrm{Rh}: \mathrm{SrTiO}_{3}$ nanocrystals. The first nanoscale titanate photocatalyst by Townsend et al. have been used for photocatalytic solar to- $\mathrm{H}_{2}$ evolution with $\mathrm{SrTiO}_{3}$, which is a large bandgap semiconductor. The activity of $\mathrm{NiO} / \mathrm{SrTiO}_{3}$ at the nanoscale is greatly reduced compared to the bulk size, which is ascribed to the decrement of light absorption into the quantum size [92]. Nickel as an electron trap reduces protons (water reduction site) and nickel oxide as a perforated trap oxidizes water [93]. Also, it has been recently concluded that the surface dimensions of $\mathrm{SrTiO}_{3}$ nanocubes in the photoelectrochemical oxidation of water affect its activity [94] and increase with increasing particle size [95]. Utilizing the perovskite-type titanate diversity as frontier materials [96], the 3D $\mathrm{SrTiO}_{3}$ architecture by hydrothermal method exhibits porous but single crystalline properties that represent a mesocrystalline, and therefore, the synthesized porous nanocubic assembly of $\mathrm{SrTiO}_{3}$ has a relatively extensive specific surface area compared to the $\mathrm{SrTiO}_{3}$ synthesized by the solid state reaction [97].

In the photocatalytic production of hydrogen from water, platinum as a cocatalyst often improves the performance of photocatalysts, but their activity is still far from the desired value. To implement the application of platinum, the cost of materials must be reduced and the efficiency of the photocatalyst must be increased with innovative methods. Clearly, the rate of production of hydrogen by $\mathrm{TiO}_{2}$, which is loaded with platinum, is higher than that of $\mathrm{TiO}_{2}$ alone [98]. Also, the photocatalytic activity of fluorinated nanosheets of $\mathrm{TiO}_{2}$ is more than titania nanoparticles in distilled water because of the synergistic effect of exposure (001) sides and fluorination. Experiments on hydrogen generation using $\mathrm{Pt} / \mathrm{TiO}_{2}-001$ have shown that it is 1160 times more efficient than $\mathrm{TiO}_{2}-001$ without cocatalyst and three times more efficient than co-catalyzed $\mathrm{TiO}_{2}-101$ with $\mathrm{Pt}$, which is a promising way to design a monoatomic photocatalyst [99]. Diffuse reflectance spectra has shown $\mathrm{TiO}_{2}-001$ and $\mathrm{TiO}_{2}-101$ have similar light absorption behaivior. But defective titania on which the Pt atom is mounted, is more efficient because $\mathrm{Pt}$, as a place to reduce protons, creates empty space in the lateral $\mathrm{TiO}_{2}$ units [100]. $\mathrm{Rh} / \mathrm{TiO}_{2}$ exhibited 10 times higher photocatalytic activities than pure titania [101]. The latest study on $\mathrm{Rh} / \mathrm{TiO}_{2}$, synthesized with deposition of $\mathrm{Ca}_{3}\left[\mathrm{Rh}(\mathrm{OH})_{6}\right]_{2}$, found a $\mathrm{H}_{2}$ generation rate of $21 \mathrm{~mol} / \mathrm{h}$ per rhodium gram consumed [102]. At room temperature, hydrogen is mainly produced from the decomposition of sacrificial reagents such as methanol instead of $\mathrm{H}_{2} \mathrm{O}$ reduction in the presence of Rh-loaded titania. Therefore, by applying thermal energy by increasing the reaction temperature under sunlight, active proton species can be transferred to water molecules [103].

Experiment has shown that the rate of hydrogen production with photocatalyst $\mathrm{Ru} / \mathrm{TiO}_{2}$ is more than that of $\mathrm{TiO}_{2}$ cocatalysts with platinum due to ruthenium electronic properties according to the arrangement $\mathrm{Ru}>\mathrm{Pt}$ [104]. However, the amount of loaded $\mathrm{Ru}$ is important so that increasing it from the allowable value reduces the efficiency of the photocatalytic system [105]. 
a)

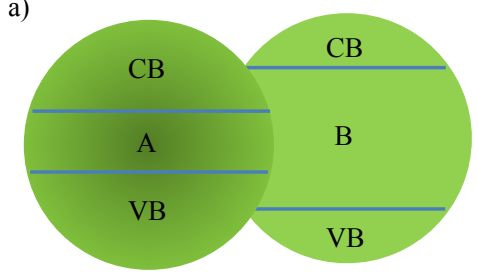

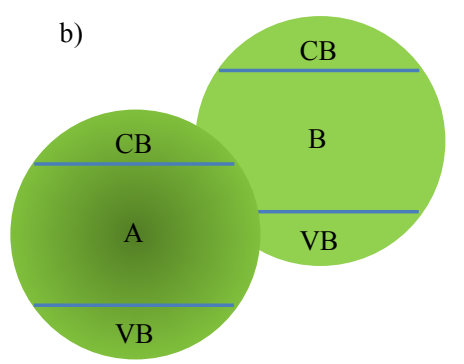

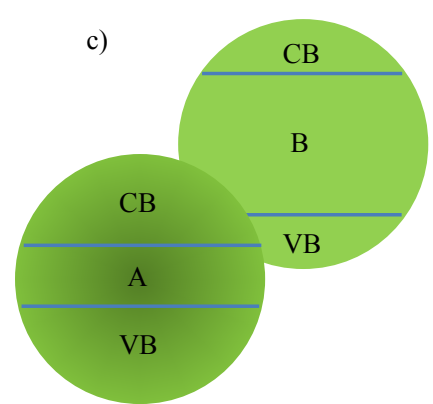

Fig. 6. Different types of heterojunctions: a) type I, b) type II, and c) type III, in which A and B correspond to semiconductors A and B, respectively.

Okamoto et al. have shown that the activity of Rh-doped $\mathrm{KCa}_{2} \mathrm{Nb}_{3} \mathrm{O}_{10}$ photocatalyst in $\mathrm{H}_{2}$ generation follows the amount of $\mathrm{Rh}$ doping. While the activity of calcium niobate photocatalyst with rhodium doped without cocatalyst is low, $\mathrm{Ca}_{2} \mathrm{Nb}_{3} \mathrm{O}_{10}$ sheets loaded with cocatalyst such as $\mathrm{NiO}, \mathrm{Rh}_{2} \mathrm{O}_{3}$ or Pt have better efficiencies [106]. Then, Nishioka et al. tested Rhodium doping on supported $\mathrm{BaTiO}_{3}$ synthesized by hydrothermal method [107]. In another study, $\mathrm{RhCrO}_{\mathrm{x}}$ loaded with $\mathrm{LaFeO}_{3}$ cocatalyst was utilizd to closely estimate the performance of photocatalytic hydrogen evolution under solar spectrum [108]. It has been discovered that the rate of $\mathrm{H}_{2}$ production in the vicinity of $\mathrm{RhCrO}_{\mathrm{x}} / \mathrm{Pr}-\mathrm{LaFeO}_{3}$ and triethanolamine (TEOA) as sacrificial agents is the highest compared to methanol and ethanol.

The "one-pot" synthesis of Ag/calcium titanate nanocrystals in aqueous dilution has been proposed by Alzahrani et al. [109]. Upon deposition of metallic Ag nanoparticles on $\mathrm{CaTiO}_{3}$, hydrogen generation rate has been increased, because of the stimulation of surface plasmon resonance (SPR) in silver, increased $\mathrm{e}^{-} / \mathrm{h}^{+}$separation in $\mathrm{CaTiO}_{3}$ and narrowing of the bandgap in $\mathrm{CaTiO}_{3}$. Recently, silver was utilized on the $\mathrm{TiO}_{2}$, and silica was used to provide the highest number of surface sites, and calcination was performed on it at the optimum temperature and for the appropriate time [110]. Hydrogen generation rate on silicasupported $\mathrm{Ag}-\mathrm{TiO}_{2}$ is 4.5 and 10 times greater than calcined $\mathrm{TiO}_{2} / \mathrm{SiO}_{2}$ and uncalcined $\mathrm{TiO}_{2} / \mathrm{SiO}_{2}$ respectively. Previously Shang et al. had proposed mesoporous nanofibers $\mathrm{Ag} @ \mathrm{TiO} 2$, which achieved a hydrogen production rate of $531.9 \mu \mathrm{molg}^{-1} \mathrm{~h}^{-1}$ [111], which is lower than $\mathrm{Ag}-\mathrm{TiO}_{2} / \mathrm{SiO}_{2}$. However, the core-shell $\mathrm{Ag} @ \mathrm{Ni} / \mathrm{TiO}_{2}$ has also been used to produce photocatalytic hydrogen, which has yielded promising results due to synergistic effect of silver and nickle. Electrons photoexcited, which is the silver metal, are collected by the core (receptor) and the shell, which is nickel, acts as the extractor. Nickel is a suitable metal in the development of composites and its preparation is low cost because it is an abundant element in the earth's crust [112].

Recently, many researchers have drawn attention to graphitic carbon nitride-based nanocomposites [113]. Important aspects of the activity of g- $\mathrm{C}_{3} \mathrm{~N}_{4}$-based photocatalyst are: (i) the ability to absorb light, (ii) charge dissociation and transportation and (iii) reactive surface [114]. Uniqe bandgap and high chemical stability has led to the use of g- $\mathrm{C}_{3} \mathrm{~N}_{4}$ as a support in cocatalytic systems, even in the reforming of carbon dioxide [115]. Research has shown that the noble metals such as Ag [116], Pt [117], Ru [118], Pd [119] and Au [120] associated with g$\mathrm{C}_{3} \mathrm{~N}_{4}$ have excellent photocatalytic performance due to the Schottky barrier formation [121]. A synthesis strategy for the production $g-C_{3} \mathrm{~N}_{4}$ monolayer predominant nanosheets by controllable oxidization cutting method is suggested by She at al. 2D monolayer structure and oxygen modification jointly increase the photocatalytic activity with the contribution from large surface area, efficient electrons/holes separation and the enhanced bandgap [122]. However, efforts to synthesize $\mathrm{g}-\mathrm{C}_{3} \mathrm{~N}_{4}$ material continue in a simple and economical process [123]. Of course, the most practical way to improve the separation and transfer of charge carriers is to fabricationof heterojunction composites [124].

A common strategy for extending the lifespan of light-induced charge carriers is to construct a heterogeneous Z-scheme photocatalyst so that the redox potential is not reduced [125]. p-type semiconductors are able to create additional valence holes for the host atom, while n-type semiconductors are produced when impurities are able to deliver additional electrons to the host atom [126]. Fig. 6 shows three types of heterogeneous bonds to characterize the different band alignments commonly occurring in nanocomposites. Z-scheme and type II heterojunction photocatalysts have shortcomings, so the S-scheme has been proposed and is still in the study phase.

The tantalum nitride $\left(\mathrm{Ta}_{3} \mathrm{~N}_{5}\right)$ nanoparticles are preferable to bulk $\mathrm{Ta}_{3} \mathrm{~N}_{5}$ because they are more optically active, have less defective sites, and higher surface area [127]. Platinum cocatalyst enhances photoactive sites and increase the contact surface. But with $\mathrm{Pt} / \mathrm{MgO}$ (in)- $\mathrm{Ta}_{3} \mathrm{~N}_{5}$ the photocatalytic activity is much higher than $\mathrm{Pt} / \mathrm{Ta}_{3} \mathrm{~N}_{5}$ [128]. By comparing the results, it is found that $\mathrm{Ta}_{3} \mathrm{~N}_{5}$, as a semiconductor, performs better with single atoms of noble metals. Even single atoms of $\mathrm{Ru}$, Ir, and $\mathrm{Rh}$ have comparable or even better performance than single atoms of Pt [129]. Therefore, $\mathrm{Ta}_{3} \mathrm{~N}_{5}$ can be a noteworthy candidate for the photocatalytic generation of $\mathrm{H}_{2}$ under sunlight by doping single atom of noble metals. However, there is a volcanic relationship between photocatalyst activity and the amount of cocatalyst loaded, as shown in Fig. 7. Initially, by adding a cocatalyst to the semiconductor, the photocatalytic activity increases to a maximum. Then more cocatalyst loading leads to a downward trend in photocatalytic activity [130].

To increase the efficiency of solar energy, it must be possible to control the location of the cocatalyst on the semiconductors to comfort charge carrier transfer and to prevent $\mathrm{e}^{-} / \mathrm{h}^{+}$ recombination. By depositing platinum on the surface of carbon sulfide while $\mathrm{Si}$ deposited sites are under control, electron transfer can be accelerated to lead to a water-splitting reaction 


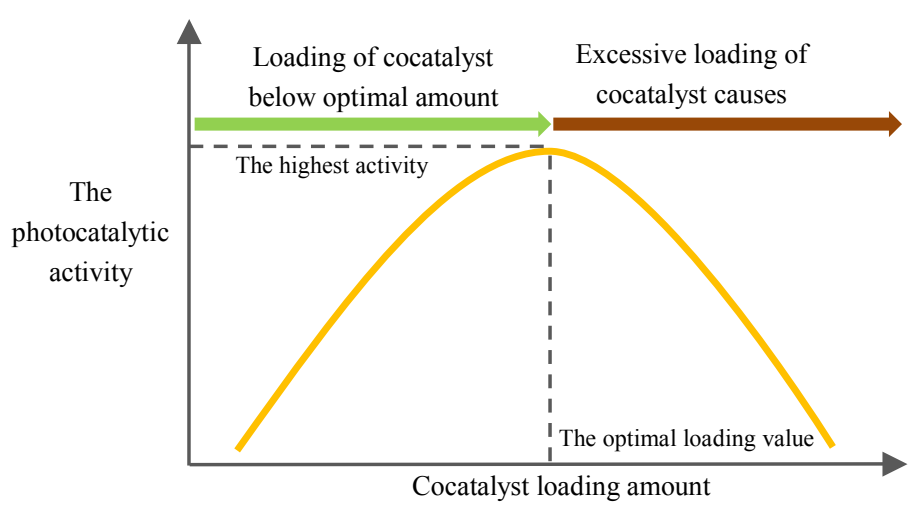

Fig. 7. The relationship between the activity of photocatalyst and the loading amount of cocatalyst.

[131]. Simultaneous deposition of $\mathrm{Pt}$ and $\mathrm{IrO}_{2}$ on the $\mathrm{SiC}$ surface can increase the rate of hydrogen production from 1376 $\mu \mathrm{Lg}^{-1} \mathrm{~h}^{-1}$ to $2337 \mu \mathrm{Lg}^{-1} \mathrm{~h}^{-1}$, while the activity of $\mathrm{Pt} / \mathrm{IrO}_{2} / \mathrm{SiC}$ is 130 times that of pure $\mathrm{SiC}$ [132]. Because $\mathrm{IrO}_{2}$ has little potential for the water-splitting reaction, it should not be used alone and should be placed on a composite base. However, with the synthesis of $\mathrm{Pt} / \mathrm{SiC}$ nanowire by hydrothermal synthesis, the rate of hydrogen production reaches $4572 \mu \mathrm{Lg}^{-1} \mathrm{~h}^{-1}$ [133]. The photocatalytic compounds studied for hydrogen generation are presented in table 1 .

Table 1. List of photocatalytic compounds for hydrogen production based on noble metals.

\begin{tabular}{|c|c|c|c|}
\hline Photocatalyst & Synthesis method and reaction conditions & $\mathrm{H}_{2}$ prod. rate & Ref. \\
\hline $\mathrm{Pt} / \mathrm{TiO}_{2}$ nanosheets $(001)$ & Hydrothermal route, ethanol aqueous solution, $350 \mathrm{~W}$ Xe lamp, ethanol & $16.68 \mathrm{mmolg}^{-1} \mathrm{~h}^{-1}$ & [98] \\
\hline $\mathrm{Pt} / \mathrm{TiO}_{2}-001$ & Deposition precipitation, Xe lamp $300 \mathrm{~W}$ (CEL-HXF300), $0.1 \mathrm{M}$ methanol & $21.9 \mathrm{mmolg}^{-1} \mathrm{~h}^{-1}$ & [99] \\
\hline Single $\mathrm{Pt}$ atoms on defective $\mathrm{TiO}_{2}$ & Xe lamp $300 \mathrm{~W}$ (CEL-HXF300), 0.1 M methanol & $52.7 \mathrm{mmolg}^{-1} \mathrm{~h}^{-1}$ & {$[100]$} \\
\hline $\begin{array}{lll}\text { Rh-doped } & \mathrm{TiO}_{2} & \text { single-crystal } \\
\text { nanosheets } & & \end{array}$ & Thermal annealing, $20 \mathrm{vol} \% \mathrm{CH}_{3} \mathrm{OH}$, xenon lamp $500 \mathrm{~W}$ & $2550 \mu \mathrm{molg}^{-1} \mathrm{~h}^{-1}$ & {$[101]$} \\
\hline $\mathrm{Rh} / \mathrm{TiO}_{2}$ & Deposition, ethanol solution, $\lambda=380 \mathrm{~nm}$ & $3.3 \mathrm{mmolg}^{-1} \mathrm{~h}^{-1}$ & {$[102]$} \\
\hline $\mathrm{Ru}$ atoms/multi-edged $\mathrm{TiO}_{2}$ spheres & $\begin{array}{l}\text { Solvothermal method and calcination of as-synthesized ME-PT, } 20 \mathrm{ml} \text { of methanol, Xe lamp, } 300 \\
\mathrm{~W}\end{array}$ & $7.2 \mathrm{mmolg}^{-1} \mathrm{~h}^{-1}$ & [105] \\
\hline Rh-doped $\mathrm{Ca}_{2} \mathrm{Nb}_{3} \mathrm{O}_{10}$ sheet & Thermal annealing, $10 \mathrm{vol} \% \mathrm{CH}_{3} \mathrm{OH}$, xenon lamp $500 \mathrm{~W}$ & $77 \mathrm{mmolg}^{-1} \mathrm{~h}^{-1}$ & {$[106]$} \\
\hline $\mathrm{Ag} / \mathrm{CaTiO}_{3}$ & "One-pot" synthesis, medium pressure $\mathrm{Hg}$ lamp $450 \mathrm{~W}, 20 \mathrm{~min}, 10$ vol\% solution of glycerol & $167 \mu \mathrm{molg}^{-1} \mathrm{~h}^{-1}$ & [109] \\
\hline $\mathrm{Ag}-\mathrm{TiO}_{2} / \mathrm{SiO}_{2}$ & Hydrothermal approach, $2 \mathrm{~mL}$ of methanol and $10 \mathrm{~mL}$ of water, Xe Arc lamp $150 \mathrm{~W}$, Ar gas & $738 \mu \mathrm{molg}^{-1} \mathrm{~h}^{-1}$ & {$[110]$} \\
\hline $\mathrm{Ag} @ \mathrm{Ni} / \mathrm{TiO}_{2}$ & $\begin{array}{l}\text { One-step photoinduced deposition, four } 365 \text {-nm LEDs }\left(23.0 \mathrm{~mW} \mathrm{~cm}^{-2}\right), 20 \mathrm{~min} \text {, D-520 Nafion } \\
\text { and ethanol }(1: 1)\end{array}$ & $2934 \mu \mathrm{molg}^{-1} \mathrm{~h}^{-1}$ & {$[112]$} \\
\hline $\mathrm{Pt} @ \mathrm{O}-\mathrm{g}-\mathrm{C}_{3} \mathrm{~N}_{4}$ & Thermal oxidation, Xe lamp $300 \mathrm{~W}(\lambda>400 \mathrm{~nm}), 10$ vol \% TEOA & $8875 \mu \mathrm{molg}^{-1} \mathrm{~h}^{-1}$ & [122] \\
\hline $\mathrm{Pt} / \mathrm{Ta}_{3} \mathrm{~N}_{5}$ nanoparticles & $\mathrm{MeOH} 20$ vol$\%$, Hg lamp $450 \mathrm{~W}, 5 \mathrm{~h}, 2 \mathrm{M} \mathrm{NaNO}_{2}$ filter $(\lambda>400 \mathrm{~nm})$ & $136 \mu \mathrm{molg}^{-1} \mathrm{~h}^{-1}$ & {$[127]$} \\
\hline $\mathrm{Pt}-\mathrm{CuS} / \mathrm{ZnIn}_{2} \mathrm{~S}_{4}$ & $\begin{array}{l}\text { Assisted hydrothermal method, Ar carrier, } 0.35 \mathrm{M} \mathrm{Na}_{2} \mathrm{~S}-0.25 \mathrm{M} \mathrm{Na}_{2} \mathrm{SO}_{3} \text { mixed in } 100 \mathrm{~mL} \text { water, } \\
300 \mathrm{~W} \text { solar simulator }\end{array}$ & $4 \mathrm{mmolg}^{-1} \mathrm{~h}^{-1}$ & {$[134]$} \\
\hline D149/Protonated g- $\mathrm{C}_{3} \mathrm{~N}_{4}(\mathrm{pCN}) \mathrm{Pt}$ & $\begin{array}{l}\text { Calcination method, } 18 \mathrm{~mL} \text { aqueous solution, } 0.81 \mathrm{mg} \mathrm{H}_{2} \mathrm{PtCl}_{6} \cdot 6 \mathrm{H}_{2} \mathrm{O}, 2 \mathrm{~mL} \text { triethanolamine } \\
\text { (TEOA), } 300 \text { WXe lamp, } \lambda>420 \mathrm{~nm}, 12{ }^{\circ} \mathrm{C}\end{array}$ & $2138 \mu \mathrm{molg}^{-1} \mathrm{~h}^{-1}$ & [135] \\
\hline $\mathrm{Pd} / 2 \mathrm{D} \mathrm{C}_{3} \mathrm{~N}_{4}$ & $\begin{array}{l}\text { Hydrothermal method, oil bath method for Pd nanotubes preparation, } 100^{\circ} \mathrm{C}, 90 \mathrm{~mL} \text { water and } 10 \\
\text { mL TEOA, } 300 \mathrm{~W} \text { Xe lamp, } \lambda>400 \mathrm{~nm}\end{array}$ & $1208.6 \mu \mathrm{molg}^{-1} \mathrm{~h}^{-1}$ & {$[136]$} \\
\hline 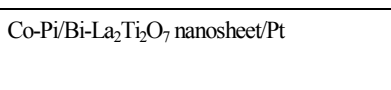 & $\begin{array}{l}\text { Hydrothermal method, room temperature, methanol } 20 \mathrm{vol} \%, 0.1 \mathrm{M} \mathrm{AgNO}_{3} \text {, Xe light source, } \\
(\lambda>400 \mathrm{~nm})\end{array}$ & $8 \mathrm{mmolg}^{-1} \mathrm{~h}^{-1}$ & {$[137]$} \\
\hline $\begin{array}{l}\text { Ptblack } \quad \mathrm{TiO}_{2-\mathrm{x}} \quad \text { crystalline } \quad \text { core- } \\
\text { amorphous shell }\end{array}$ & $\begin{array}{l}\text { Impregnation ,300 W Xe lamp, } 5 \mathrm{~h}, 20 \% \text { methanol, } \mathrm{TiO}_{2-\mathrm{x}} \text { was reduction at } 300{ }^{\circ} \mathrm{C} \text { denoted as } \\
\mathrm{T} 300\end{array}$ & $5.2 \mathrm{mmolg}^{-1} \mathrm{~h}^{-1}$ & {$[138]$} \\
\hline $\mathrm{AuNPs} 0.5 \% / \mathrm{TiO}_{2}(\mathrm{P} 25)$ & $\begin{array}{l}\text { The Duff and Baiker method, closed Pyrex glass reactor, an argon atmosphere, } 25 \mathrm{v} \% \mathrm{CH}_{3} \mathrm{OH}, \lambda= \\
400\end{array}$ & $63 \mathrm{mmolg}^{-1} \mathrm{~h}^{-1}$ & {$[139]$} \\
\hline $\mathrm{TiO}_{2}-\mathrm{Au}$ composite nanofibers & $\begin{array}{l}\text { Electrospinning (ES) combined with subsequent calcination, xenon arc lamp } 300 \mathrm{~W}, 3 \mathrm{~h} \text {, } \\
\text { methanol/water 1:9 under ultrasonic, argon }\end{array}$ & $12440 \mu \mathrm{molg}^{-1} \mathrm{~h}^{-1}$ & {$[140]$} \\
\hline
\end{tabular}


Table 1. continued.

\begin{tabular}{|c|c|c|c|}
\hline $\mathrm{Au} / \mathrm{TiO}_{2}(\mathrm{P} 25)-\mathrm{gC}_{3} \mathrm{~N}_{4}$ & $\begin{array}{l}\text { Thermal polycondensation, } 1 \% \mathrm{v} \text { triethanolamine, quartz vessel, Milli-Q deionized } \mathrm{H}_{2} \mathrm{O}(1 \mathrm{~L}) \text {, } \\
\text { nigrosing solution, ceramic-metal-halide } \mathrm{Hg} \text { lamp } 150 \mathrm{~W}\end{array}$ & $419 \mu \mathrm{molg}^{-1} \mathrm{~h}^{-1}$ & [141] \\
\hline $\mathrm{Au} / \mathrm{TiO}_{2}-\mathrm{gC}_{3} \mathrm{~N}_{4}$ & Sol-gel procedure and calcination, methanol $<1 \mathrm{vol} \%, 150 \mathrm{~W}$ Hg lamp, $1000 \mathrm{~mL}$ MilliQ water & $570 \mu \mathrm{molg}^{-1} \mathrm{~h}^{-1}$ & [142] \\
\hline $\mathrm{Au} / \mathrm{BiVO}_{4} / \mathrm{g}_{-} \mathrm{C}_{3} \mathrm{~N}_{4}$ & $\begin{array}{l}\text { Calcination method, } 20 \mathrm{~mL} \text { triethanolamine in } 80 \mathrm{~mL} \text { ultrapure water, Ar gas, xenon lamp } 300 \mathrm{~W} \\
(\lambda \geq 420 \mathrm{~nm}) \text {, }\end{array}$ & $410 \mu \mathrm{molg}^{-1} \mathrm{~h}^{-1}$ & [143] \\
\hline $\mathrm{Ag} \mathrm{NPs} / \mathrm{SrTiO}_{3}$ perovskite nanocubes & $\begin{array}{l}\text { Hydrothermal synthesis, ethanol-water scavenger suspension }(100: 100 \mathrm{~mL}), \mathrm{UV}-\text { low pressure Hg lamp, } \lambda= \\
254 \mathrm{~nm}\end{array}$ & $463 \mu \mathrm{molg}^{-1} \mathrm{~h}^{-1}$ & [144] \\
\hline $\mathrm{Rh}-\mathrm{Ti}_{3} \mathrm{NS}$ & $\begin{array}{l}\text { Solid-state reaction method, water solution ( } \mathrm{pH} \mathrm{11)} \text {, triethylamine (TEA) as an electron donor, } \\
500 \mathrm{~W} \text { Xe lamp, } \lambda>220 \mathrm{~nm}\end{array}$ & $1970 \mu \mathrm{molg}^{-1} \mathrm{~h}^{-1}$ & [145] \\
\hline $\mathrm{Pt} @ \mathrm{Cu}_{1.94} \mathrm{~S}-\mathrm{Zn}_{\mathrm{x}} \mathrm{Cd}_{1-\mathrm{x}} \mathrm{S} 1 \mathrm{D}, 0 \leq \mathrm{x} \leq 1$ & $\begin{array}{l}\text { In-situ photodeposited Pt nanoparticles (NPs) }\left(5 \mathrm{wt} \% \text { ), deionized water, } 0.1 \mathrm{M} \mathrm{Na}_{2} \mathrm{SO}_{3} \text { and } 0.1 \mathrm{M}\right. \\
\mathrm{Na}_{2} \mathrm{~S}, 50 \mathrm{~mL} / 20 \mathrm{mg}, \lambda>420 \mathrm{~nm}\end{array}$ & $13533 \mu \mathrm{molg}^{-1} \mathrm{~h}^{-1}$ & [146] \\
\hline Pt/black TiO ${ }_{2} @ \mathrm{TiO}_{2-\mathrm{x}} \mathrm{H}_{\mathrm{x}}$ (core/shell) & Photodeposition method, methanol, AM $1.5\left(100 \mathrm{~mW} \mathrm{~cm}^{-2}\right)$ & $10 \mathrm{mmolg}^{-1} \mathrm{~h}^{-1}$ & [147] \\
\hline $\mathrm{Pd}-\mathrm{CdS} / \mathrm{g}-\mathrm{C}_{3} \mathrm{~N}_{4}$ & $\begin{array}{l}\text { Hydrothermal method, } 100 \mathrm{~mL} \text { aqueous solution, } 0.5 \mathrm{M} \mathrm{Na}_{2} \mathrm{SO}_{3} \text { and } 0.5 \mathrm{M} \mathrm{Na}_{2} \mathrm{~S}, \mathrm{Xe} \text { lamp } 300 \mathrm{~W} \\
\text { a } 420 \mathrm{~nm} \text { cut-off filter, } 2 \mathrm{~h}\end{array}$ & $293 \mu \mathrm{molg}^{-1} \mathrm{~h}^{-1}$ & [148] \\
\hline $\mathrm{Pt} / \mathrm{CoO}_{\mathrm{x}} / \mathrm{TiO}_{2}$ & Atomic layer deposition with assisted template, Xe lamp $300 \mathrm{~W}$ & $275.9 \mu \mathrm{mol} \mathrm{h}^{-1}$ & [149] \\
\hline $\mathrm{RuO}_{2} / \mathrm{CeO}_{2}: \mathrm{Sr}$ & Calcination, 400-450W high pressure Hg lamp with a quartz cell, distilled water & $100 \mu \mathrm{molg}^{-1} \mathrm{~h}^{-1}$ & {$[150]$} \\
\hline $\mathrm{RuO}_{2} / \mathrm{BaCeO}_{3}$ & Pechini-type process, Hg lamp $400 \mathrm{~W}, 50 \mathrm{~mL}$ methanol and $420 \mathrm{~mL}$ distilled water & $59 \mu \mathrm{molg}^{-1} \mathrm{~h}^{-1}$ & [151] \\
\hline $\mathrm{RuO}_{2} / \mathrm{Zn}_{2} \mathrm{GeO}_{4}$ & Calcination method, Ar atmosphere, $200 \mathrm{~W} \mathrm{Hg}-\mathrm{Xe}$ lamp and a quartz cell, pure water & $88 \mu \mathrm{molg}^{-1} \mathrm{~h}^{-1}$ & [152] \\
\hline $\mathrm{Pt} / \mathrm{CdS}$ nanowires & $\begin{array}{l}\text { Solvothermal method, lactic acid as sacrificial ( } 8 \mathrm{~mL} / 72 \mathrm{~mL} \text { water }), \mathrm{Xe} \text { arc lamp } 350 \mathrm{~W} \text { through a } \\
\text { cutoff filter }(\leq 420 \mathrm{~nm})\end{array}$ & $16.06 \mu \mathrm{molg}^{-1} \mathrm{~h}^{-1}$ & [153] \\
\hline $\mathrm{Pt} /$ urchin-like CdS & $\begin{array}{l}\text { Solvothermal method, lactic acid as sacrificial }(8 \mathrm{~mL} / 72 \mathrm{~mL} \text { water }), 350 \mathrm{~W} \text { Xe arc lamp through a } \\
\text { UV-cutoff filter }(\leq 420 \mathrm{~nm})\end{array}$ & $13.1 \mathrm{mmolg}^{-1} \mathrm{~h}^{-1}$ & [153] \\
\hline $\mathrm{Au} @ \mathrm{TiO}_{2} @ \mathrm{RuO}_{2}$ & Sol-gel method, 20 vol\% methanol, $300 \mathrm{~W}$ xenon arc lamp, & $527 \mu \mathrm{molg}^{-1} \mathrm{~h}^{-1}$ & [154] \\
\hline CdS- $\mathrm{Ag}_{3} \mathrm{PO}_{4}$ heteronanostructures & $\begin{array}{l}\text { Solvothermal and subsequent chemical reaction method, ambient condition, } 350 \mathrm{~W} \text { Xenon arc } \\
\text { lamp (>420 nm), 10\% methanol }\end{array}$ & $6.6 \mathrm{mmolg}^{-1} \mathrm{~h}^{-1}$ & [155] \\
\hline $\mathrm{TiO}_{2} / \mathrm{Pt} / \mathrm{rGO}$ & $\begin{array}{l}\text { Modified Hummers method, } 500 \mathrm{~W} \text { Xe lamp, ambient temperature and atmospheric pressure, } 25 \\
\mathrm{~mL} \text { methanol and } 75 \mathrm{~mL} \text { water }\end{array}$ & $876 \mu \mathrm{molg}^{-1} \mathrm{~h}^{-1}$ & [156] \\
\hline $\mathrm{Au}-\mathrm{TiO}_{2}-\mathrm{rGO}$ & $\begin{array}{l}\text { One-step microwave-assisted hydrothermal method, ambient condition, } 4 \text { low power ( } 3 \mathrm{~W} \text { ) } 420 \\
\text { nm-LEDs , } 20 \mathrm{~mL} \mathrm{CH}_{3} \mathrm{OH} \text { and } 60 \mathrm{~mL} \mathrm{H}_{2} \mathrm{O}\end{array}$ & $296 \mu \mathrm{molg}^{-1} \mathrm{~h}^{-1}$ & [157] \\
\hline $\mathrm{Pt} / \mathrm{TpPa}-1, \mathrm{C}_{3} \mathrm{~N}-\mathrm{Pt}-\mathrm{Cl}_{2}$ & $\begin{array}{l}\text { Integration method, } 400 \mathrm{mg} \text { of sodium ascorbate (SA) as a sacrificial agent in } 100 \mathrm{~mL} \text { PBS buffer } \\
\text { solution, } 300 \mathrm{~W} \text { Xe lamp, } 420 \mathrm{~nm} \text { cutoff }\end{array}$ & $719 \mu \mathrm{molg}^{-1} \mathrm{~h}^{-1}$ & [158] \\
\hline $\begin{array}{l}\mathrm{Pt} / \mathrm{TiO}_{2}(\mathrm{~N} 719 \text { dye }) \text { coated by ionic } \\
\text { liquid }\end{array}$ & & $70 \mu \mathrm{molg}^{-1} \mathrm{~h}^{-1}$ & [159] \\
\hline $\mathrm{Pt} / \mathrm{C}_{3} \mathrm{~N}_{3}-\mathrm{SO}$ & & $2966 \mu \mathrm{molg}^{-1} \mathrm{~h}^{-1}$ & [160] \\
\hline Pt-modified B-SO & & $1253 \mu \mathrm{molg}^{-1} \mathrm{~h}^{-1}$ & [160] \\
\hline $\mathrm{Ag}-\mathrm{ZnIn}_{2} \mathrm{~S}_{4}$ & Hydrothermal method, $0.25 \mathrm{M} \mathrm{Na}_{2} \mathrm{SO}_{3}$ and $0.35 \mathrm{M} \mathrm{Na}_{2} \mathrm{~S}$, xenon lamp $300 \mathrm{~W}, \lambda>420 \mathrm{~nm}$ & $7.3 \mathrm{mmolg}^{-1} \mathrm{~h}^{-1}$ & {$[161]$} \\
\hline $\mathrm{Pt} / \mathrm{Sn}_{3} \mathrm{O}_{4}$ & Hydrothermal method, $50 \mathrm{~mL}$ of methanol in distilled water, $\mathrm{H}_{2} \mathrm{PtCl}_{6} \mathrm{Xe}$ lamp $300 \mathrm{~W}, \lambda>400$ & $16.67 \mu \mathrm{molg}^{-1} \mathrm{~h}^{-1}$ & [162] \\
\hline $\mathrm{Rh}(\mathrm{NCs})-\mathrm{TiO}_{2}$ (anatase)- $\mathrm{CeO}_{2}$ & Seed-mediated methods, methanol/deionized water: 3/1, Xe lamp $300 \mathrm{~W}, \lambda>400 \mathrm{~nm}$ & $48.3 \mu \mathrm{molg}^{-1} \mathrm{~h}^{-1}$ & {$[163]$} \\
\hline $\begin{array}{l}\mathrm{Au} \quad(\text { surface } \\
\text { resonance }) / \mathrm{InVO}_{4}\end{array}$ & Hydrothermal method, electron donor: $0.1 \mathrm{~mL}$ ascorbate, $\mathrm{pH}=4$, Xe lamp $300 \mathrm{~W}, \lambda>420 \mathrm{~nm}$ & $116.7 \mu \mathrm{molg}^{-1} \mathrm{~h}^{-1}$ & {$[164]$} \\
\hline Heterojunction formed $\mathrm{Ag}_{3} \mathrm{PO}_{4}-\mathrm{TiO}_{2}$ & In-situ precipitation, $25 \mathrm{~mL} 20 \mathrm{vol} \% \mathrm{MeOH}$, Xe lamp $300 \mathrm{~W}$ and solar filter (AM 1.5), $25^{\circ} \mathrm{C}$ & $44.5 \mu \mathrm{molg}^{-1} \mathrm{~h}^{-1}$ & [165] \\
\hline $\mathrm{Pt} / \mathrm{g}-\mathrm{C}_{3} \mathrm{~N}_{4} / \mathrm{BiOBr} \mathrm{S}$-scheme & Solvothermal method & $361 \mu \mathrm{molg}^{-1} \mathrm{~h}^{-1}$ & [166] \\
\hline $\mathrm{Rh} / \mathrm{CuGa}_{3} \mathrm{~S}_{5}$ & Hydrothermal method, $10 \mathrm{mM} \mathrm{Na}_{2} \mathrm{~S}$ and $10 \mathrm{mM} \mathrm{Na}_{2} \mathrm{SO}_{3}$, Xe lamp $300 \mathrm{~W}, 420<\lambda<520$ & $1000 \mu \mathrm{molg}^{-1} \mathrm{~h}^{-1}$ & [167] \\
\hline $\begin{array}{l}\mathrm{Rh} / \mathrm{Cr}_{2} \mathrm{O}_{3} \\
\text { shell) } /\left(\mathrm{Ga}_{1-\mathrm{x}} \mathrm{Zn}_{\mathrm{x}}\right)\left(\mathrm{N}_{1-\mathrm{x}} \mathrm{O}_{\mathrm{x}}\right)\end{array}$ & In situ photodeposition method, $\mathrm{Hg}$ lamp $450 \mathrm{~W}, \mathrm{NaNO}_{2} 2 \mathrm{M}$ solution, $\lambda>400 \mathrm{~nm}$ & $1.16 \mathrm{mmolg}^{-1} \mathrm{~h}^{-1}$ & [168] \\
\hline $\mathrm{Ag}_{2} \mathrm{~S}$ nanoparticle-decorated $\mathrm{MoS}_{2}$ & $\begin{array}{l}\text { In situ growth, Xe lamp } 450 \mathrm{~W} \text { with an } \mathrm{AM} 1.5 \mathrm{G} \text { filter, ambient temperature, } 10 \mathrm{vol} \% \text { lactic acid } \\
\text { as a sacrificial agent }\end{array}$ & $628 \mu \mathrm{molg}^{-1} \mathrm{~h}^{-1}$ & [169] \\
\hline $\mathrm{Ag}_{2} \mathrm{~S} @ \mathrm{MoS}_{2} 2$ Core-Shell & $\begin{array}{l}\text { Sulfurizing } \mathrm{Ag} \text { nanowires and growing } \mathrm{MoS}_{2} \text { shell simultaneously, formaldehyde as hole } \\
\text { sacrificial agent, } 420<\lambda<780\end{array}$ & $141.6 \mathrm{mmolg}^{-1} \mathrm{~h}^{-1}$ & [170] \\
\hline $\mathrm{PdS} / \mathrm{CdS}$ & In situ coprecipitation and hydrothermal method, $\mathrm{Na}_{2} \mathrm{SO}_{3}$ and $\mathrm{Na}_{2} \mathrm{~S}$ as sacrificial reagents & $4500 \mu \mathrm{molg}^{-1} \mathrm{~h}^{-1}$ & [171] \\
\hline
\end{tabular}


Indium vanadium $\left(\mathrm{InVO}_{4}\right)$ is one of the most used semiconductors in the photocatalytic processes, which due to its thermal and chemical resistance and bandgap can have proper performance in hydrogen production [49]. But the use of $\mathrm{InVO}_{4}$ has not been developed because it has little ability to absorb solar energy. To increase the efficiency of hydrogen production, $\mathrm{InVO}_{4}$ is modified with gold nanoparticles whose surface plasmons stimulate $\mathrm{InVO}_{4}$ [164]. $\mathrm{InVO}_{4}$ can produce 140.8 $\mu \mathrm{mol} / \mathrm{g}_{\mathrm{cat}}$ hydrogen in methanol solution in the vicinity of a xenon lamp $300 \mathrm{~W}$ provided that its hydrothermal synthesis conditions such as temperature and $\mathrm{pH}$ are controlled [172].

\subsection{Dual noble metals photocatalysts}

Recent research has shown that photocatalysts designed with two noble metals, such as Pd-Pt, Au-Pt and Ag-Pt, perform better in producing photocatalytic hydrogen. Platinum group metals with group 10 and 11 metals have been used for alloying and forming intermetallic materials i.e. Pt-Cu, Pd-In, Pd-Ag. Bimetallic-based cocatalysts are an attractive strategy for the photocatalytic water splitting because they separate the charge carriers better than their single-metal counterparts [173]. Besides, the use of solar energy increases due to the intensification of surface plasmonic effects [50]. Also, in the reducing photocatalysts, Gibbs energy of hydrogen adsorption decreases by bimetallic cocatalysts. Noble metals have low Fermi levels that can trap photoproduced electrons by forming a Schottky barrier and prevent recombination of charge carriers. Therefore, in bimetallic systems, all factors including particle size, metal structure, composition and loading amount of metals must be investigated.

\subsubsection{Plasmonic bi-noble metal photocatalysts}

Gold and silver are noble metals exhibit large surface plasmonic effects that cause high absorption of visible light and a strong electric field on their surface. Plasma hybridization regulates the adsorption band by adjusting the ratio of silver to gold in $\mathrm{Ag}_{\mathrm{x}}-\mathrm{Au}_{1-\mathrm{x}}$ nanoparticles [174]. The Schottky barrier can also be raised with the optimal ratio of alloy metals used. The subnano sized Pt-Au was used by Cheng et al. for the first time [175]. The use of Pt-Au alloy on a sub-nanoscale can increase the rate of hydrogen production by up to 60 times compared to platinum and gold alone. Alloy clusters improve photocatalytic activity due to their high dispersion and the provision of active sites and synergistic effects of the two metals [176]. By adjusting the electronic structures of materials, catalysts with increased activity can be developed. The energy of hydrogen adsorption by the second metal can be tuned. Catalyst manufacturing process, type of support, capacity status and particle size affect the activity of platinum-based cocatalysts [177].

Strontium titanate-based materials are promising new materials used to produce hydrogen from solar energy. The $\mathrm{Rh}: \mathrm{SrTiO}_{3}$ monocrystalline film modified with $\mathrm{Pt} / \mathrm{Ru}$ on a gold substrate (Au) shown in Fig. 8 for hydrogen evolution has been investigated. The results show that platinum/ruthenium cocatalysts are effective in both charge separation in the adsorbent and redox reaction [178]. The results show that platinum/ruthenium cocatalysts are effective in both charge separation in the adsorbent and redox reaction [178]. For this purpose, different voltages have been used to inject the hole into $\mathrm{K}_{4}\left[\mathrm{Fe}(\mathrm{CN})_{6}\right]$, $\mathrm{K}_{3}\left[\mathrm{Fe}(\mathrm{CN})_{6}\right]$, $\mathrm{KI}$ and methanol. These voltages are particularly effective in the photocatalytic performance of the cocatalyst. Adding

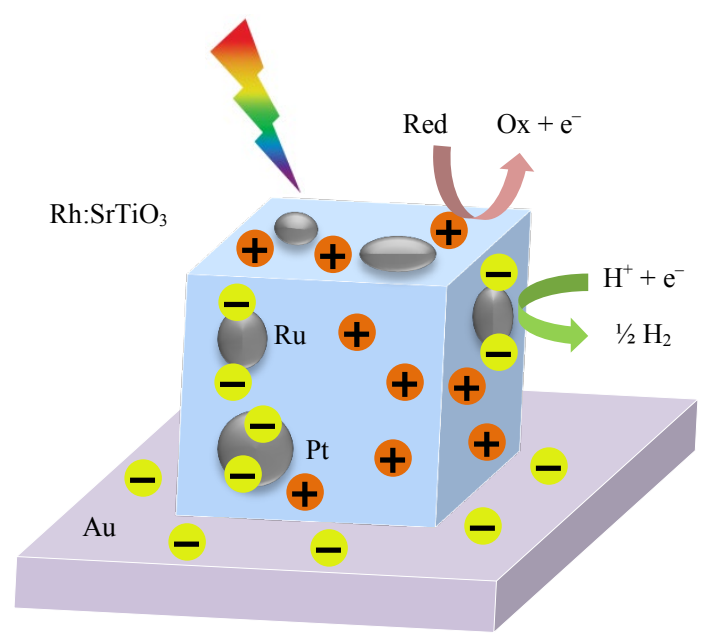

Fig. 8. The $\mathrm{Rh}: \mathrm{SrTiO}_{3}$ monocrystalline film modified with $\mathrm{Pt} / \mathrm{Ru}$ on a gold substrate.

methanol, $\mathrm{K}_{4}\left[\mathrm{Fe}(\mathrm{CN})_{6}\right]$ or $\mathrm{KI}$ as an electron donor (in pure form) dramatically increases the film voltage. Of course, La- and Rh-codoped $\mathrm{SrTiO}_{3}(\mathrm{SrTiO}: \mathrm{La} / \mathrm{Rh})$, produced with solid state method during a two-step reaction, perform much better than $\mathrm{Rh}$-doped $\mathrm{SrTiO}_{3}$ with $\mathrm{Pt}$ on $\mathrm{Au}$. Here $\mathrm{SrTiO}_{3}$ is a perovskite host, and $\mathrm{SrTiO}_{3}: \mathrm{La} / \mathrm{Rh}$ has a core/shell structure. La doping suppresses inactive $\mathrm{Rh}^{4+}$ species and the formation of oxygen voids [90]. Wang et al. examined the effect of annealing temperature on the activity of $\mathrm{Ru}: \mathrm{La}, \mathrm{Au} / \mathrm{Rh} / \mathrm{BiVO}_{4}$ : Momodified $\mathrm{SrTiO}_{3}$ nanosheet and showed that by annealing the electrical relays were amplified and the suppression of undesirable reactions increased [179].

\subsubsection{Non-plasmonic bi-noble-metal photocatalysts}

Non-plasmonic noble metals such as platinum and palladium simultaneous loading improve photocatalytic performance compared to single-platinum and single-palladium cocatalysts [180]. Of course, the morphology or crystal structure of the base cocatalyst should not be damaged by the decoration of Pt-Pd nanoparticles. Therefore, the method of loading metals is important. In a study of the Pt-Pd nanoparticles on $\mathrm{g}_{-} \mathrm{C}_{3} \mathrm{~N}_{4}$, Xiao et al. found a high rate of hydrogen production, because of the efficient charge transfer in the graphitic/PtPd NPs. Palladium is oxidized in almost all mono- and bimetallic catalysts under reaction, while oxidation of Pt-Pd alloy has not been observed, so platinum richness is useful in this compound [181]. In PtPd nanoparticles, the produced photoelectrons are more likely to be transferred to the metals interface because the joint surface of the metals has a higher energy and the separation of $\mathrm{e}^{-}$and $\mathrm{h}^{+}$produced by light is easier.

Bai et al. by plotting photocurrents versus time for different samples $\mathrm{TiO}_{2}$ cocatalysts at $\lambda<400 \mathrm{~nm}$ found that quasi-core-shell cocatalysts are effective at separating charge carriers $\left(\mathrm{Pd}_{0} \mathrm{Pt}_{3 \mathrm{~L}}-\mathrm{TiO}_{2}>\mathrm{Pd} @ \mathrm{Pt}_{10 \mathrm{~L}}-\right.$ $\mathrm{TiO}_{2}>\mathrm{Pt}-\mathrm{TiO}_{2}>\mathrm{Pd}-\mathrm{TiO}_{2}>\mathrm{TiO}_{2}$ ) [182]. Combining a Schottky junction causes enhance lattice strain, lectron density and adsorption of $\mathrm{H} 2 \mathrm{O}$ onto platinum surface. Also, required electron trapping is promote with Pt shell in atomic state.

Due to the uncomon structural and physico-chemical characteristics of two dimentional compounds in multilayer or monolayer construct, it 
has attracted widespread attention as an optimistic photocatalytic system with some advantages [183]: i), the specific surface area of semiconductors is increased and most active sites can be located on the surface and participate in the photocatalysis [184], ii) the recombination of $\mathrm{e}^{-} / \mathrm{h}^{+}$is reduced due to their very thin character [185], and iii) by changing the number of layers, the light absorption and bandgap of two dimensional semiconductor can be tuned [186]. Recently, among many 2D photocatalyst with just a few layers or single-layer structure, graphene-based photocatalysts, 2D oxides, 2D chalcogenides, 2D graphitic carbon nitride $\left(\mathrm{g}-\mathrm{C}_{3} \mathrm{~N}_{4}\right)$, and other $2 \mathrm{D}$ semiconductors begin to draw great attention in photocatalysis. Recently, some 2D semiconductor with multi-layer or mono-layer construct such as g-C3N4, chalcogenides graphene and graphene based materials have attracted many attention in photocatalytic reactions. A list of some these materials and their production methods are presented in table 2 .

Table 2. Typical bi-noble metallic photocatalyst system in $\mathrm{H}_{2}$ evolution from water splitting.

\begin{tabular}{|c|c|c|c|}
\hline Photocatalyst & Reaction conditions & $\mathrm{H}_{2}$ prod. rate & Ref. \\
\hline $\mathrm{Pt}_{\mathrm{x}} \mathrm{Au}_{100-\mathrm{x}} / \mathrm{C}_{3} \mathrm{~N}_{4}$ composite & Laser ablation and ex-situ deposition, 10 vol\% TEOA solution, Xenon lamp $300 \mathrm{~W}, \lambda>420$ & $1.6 \mathrm{mmolg}^{-1} \mathrm{~h}^{-1}$ & [173] \\
\hline $\mathrm{Ag}_{\mathrm{x}} \mathrm{Au}_{1-\mathrm{x}} \mathrm{NPs}$ alloy $/ \mathrm{ZnIn}_{2} \mathrm{~S}_{4}$ (ZIS) & $\begin{array}{l}\text { Solvothermal method, } 0.8406 \mathrm{~g} \mathrm{Na}_{2} \mathrm{~S} \cdot 9 \mathrm{H}_{2} \mathrm{O} \text { and } 0.3151 \mathrm{~g} \mathrm{Na}_{2} \mathrm{SO}_{3} \text { in distilled water }(10 \mathrm{~mL}), 300 \mathrm{~W} \\
\text { Xe lamp }\end{array}$ & $5500 \mu \mathrm{molg}^{-1} \mathrm{~h}^{-1}$ & [174] \\
\hline $\mathrm{Pt}-\mathrm{Au}$ alloy with subnano size/ $/ \mathrm{TiO}_{2}$ & Ligands-assist chemical reduction method, methanol & $80.1 \mu \mathrm{mol} \mathrm{h}^{-1}$ & {$[175]$} \\
\hline $\mathrm{Pt} /$ modified Rh-doped $\mathrm{SrTiO}_{3}$ & aqueous $\mathrm{K}_{4}\left[\mathrm{Fe}(\mathrm{CN})_{6}\right] 0.05 \mathrm{M}$, Xe lamp $300 \mathrm{~W}$ with filter, $\lambda>400 \mathrm{~nm}$, neutral pH & $50 \mu \mathrm{molg}^{-1} \mathrm{~h}^{-1}$ & [178] \\
\hline $\mathrm{La}, \mathrm{Rh} / \mathrm{Au}: \mathrm{SrTiO}_{3} / \mathrm{BiVO}_{4}: \mathrm{Mo}$ sheet & Particle transfer method, distilled water ( $\mathrm{pH} 6.8)$, Xe lamp $300 \mathrm{~W}(\lambda>420 \mathrm{~nm})$ at $573 \mathrm{~K}$ and $5 \mathrm{kPa}$. & $95 \mu \mathrm{molh}^{-1}$ & [179] \\
\hline $\begin{array}{l}\text { PtPd nanoparticles }(\mathrm{NPs}) / \mathrm{g}-\mathrm{C}_{3} \mathrm{~N}_{4} \\
\text { nanosheet }\end{array}$ & $\begin{array}{l}\text { Chemical deposition precipitation, } 10 \mathrm{~mL} \text { of TEOA and } 90 \mathrm{~mL} \text { of deionized } \mathrm{H}_{2} \mathrm{O}, 10 \mathrm{~g} \mathrm{~K} \mathrm{HPO}_{4} \mathrm{Xe} \\
\text { arc lamp } 300 \mathrm{~W}, \lambda>400 \mathrm{~nm}, 4{ }^{\circ} \mathrm{C}\end{array}$ & $2885 \mu \mathrm{molg}^{-1} \mathrm{~h}^{-1}$ & [180] \\
\hline Pt-Pd Nb-doped $\mathrm{TiO}_{2}$ & $\begin{array}{l}\text { Hydrothermal and deposition method, } \mathrm{Hg} \text {-Xe lamp }(500 \mathrm{~W}) \text { and dichroic filters, cutting absorption } \\
\text { edge at ca. } 300 \mathrm{~nm}, 420-680 \mathrm{~nm} \text {, methanol }\end{array}$ & $4.5 \mathrm{mmolg}^{-1} \mathrm{~h}^{-1}$ & [181] \\
\hline Pd@Pt quasi-core-shell/ $/ \mathrm{TiO}_{2}$ & Hydrothermal process, $\lambda<400 \mathrm{~nm}, 2.7 \mathrm{mWcm}^{-2}, 25 \mathrm{~mL}$ methanol and $75 \mathrm{~mL}$ water & $600 \mu \mathrm{molg}^{-1} \mathrm{~h}^{-1}$ & [182] \\
\hline $\mathrm{Pt}$ and $\mathrm{Au}$ co-loading on $\mathrm{g}-\mathrm{C}_{3} \mathrm{~N}_{4}$ & Traditional photodeposition method & & [187] \\
\hline Pt-Au NPs/g- $\mathrm{C}_{3} \mathrm{~N}_{4}$ sheets & Solvothermal reduction in DMF, $0.25 \mathrm{M} \mathrm{Na}_{2} \mathrm{~S}$ with $0.25 \mathrm{M} \mathrm{Na}_{2} \mathrm{SO}_{3}$, Xe lamp $300 \mathrm{~W}, 5 \mathrm{~h}, 43-45^{\circ} \mathrm{C}$ & $1.01 \mathrm{mmolg}^{-1} \mathrm{~h}^{-1}$ & [188] \\
\hline $\mathrm{Au}-\mathrm{Pd} / \mathrm{TiO}_{2}$ & $2.7 \mathrm{M}$ formic acid, AM 1.5 sunlight, $5 \mathrm{mg} / 10 \mathrm{~mL}$ & 17.7 & [189] \\
\hline $\begin{array}{l}\mathrm{BiVO}_{4}-\mathrm{Ru} / \mathrm{SrTiO}_{3}: \mathrm{Rh} \text { composite } \mathrm{Z}- \\
\text { scheme }\end{array}$ & $\begin{array}{l}\text { Liquid-solid state reaction and impregnation, Xe lamp } 300 \mathrm{~W},(420 \mathrm{~nm}<\lambda<800 \mathrm{~nm}), \mathrm{BiVO}_{4} \text { to } \\
\mathrm{Rh} @ \mathrm{Ru} / \mathrm{SrTiO}_{3} \text { in weight=2.5 }\end{array}$ & $47.2 \mu \mathrm{molh}^{-1}$ & [190] \\
\hline $\mathrm{RuO}_{2} / \mathrm{TiO}_{2} / \mathrm{Pt}\left(\mathrm{NaBH}_{4}\right)$ & $300 \mathrm{~W}$ Xenon lamp (>420nm), the light intensity: $200 \mathrm{~mW} / \mathrm{cm}^{2}, 0.2 \mathrm{M}$ methanol, & $6126.6 \mu \mathrm{molh}^{-1}$ & [191] \\
\hline $\mathrm{Pd}-\mathrm{IrO} / \mathrm{TiO}{ }_{2}$ & $\begin{array}{l}\text { Calcining method, } 300 \mathrm{~W} \text { top-irradiated xenon lamp, methanol aqueous solution ( } 20 \mathrm{vol} \%) \text { or a } \\
\text { formic acid aqueous solution }(0.5 \mathrm{vol} \%) \text {, }\end{array}$ & $7740 \mu \mathrm{molg}^{-1} \mathrm{~h}^{-1}$ & [192] \\
\hline $\mathrm{RuO}_{2} @ \mathrm{TiO}_{2} @ \mathrm{Pt}$ & Multiple strategy, $\mathrm{T}=30^{\circ} \mathrm{C}, 4 \mathrm{LED}$ lamps, $\lambda=365 \mathrm{~nm}, 60 \mathrm{~mL}$ water and $20 \mathrm{~mL}$ methanol, & $4200 \mu \mathrm{molg}^{-1} \mathrm{~h}^{-1}$ & [193] \\
\hline $\mathrm{Au}-\mathrm{TiO}_{2}-\mathrm{Pt}$ nanodumbbells & $\begin{array}{l}\text { The chemical reduction method, aqueous solution of methanol: } \mathrm{v} / \mathrm{v} 20 \% \text {, A Xe lamp coupled filter } \\
\text { AM } 1.5 \mathrm{G}(\lambda>420 \mathrm{~nm})\end{array}$ & $344.6 \mu \mathrm{molg}^{-1} \mathrm{~h}^{-1}$ & [194] \\
\hline Pt $1 \% \mathrm{wt} / \mathrm{Ag} / \mathrm{Ga}_{2} \mathrm{O}_{3}$ nanofibers & $\begin{array}{l}\text { Electrospinning method, } 50 \mathrm{~mL} \text { water, } 10 \mathrm{vol} \% \mathrm{CH}_{3} \mathrm{OH} \text { (electron donor), Xe lamp } 300 \mathrm{~W}, 2 \mathrm{~h}, 20 \\
{ }^{\circ} \mathrm{C}\end{array}$ & $1095 \mu \mathrm{molg}^{-1} \mathrm{~h}^{-1}$ & [195] \\
\hline $\begin{array}{ll}\text { Nanostructured } \\
\text { (heteronanostructure) }\end{array} \quad \mathrm{Ag}_{2} \mathrm{~S} / \mathrm{Ag}$ & $\begin{array}{l}\text { Hydrochemical bath deposition, } \mathrm{Na}_{2} \mathrm{~S}, \mathrm{Na}_{2} \mathrm{SO}_{3}, \mathrm{pH}=12,450 \mathrm{~nm} \text { wavelength light-emitting diode } \\
\text { (LED) }\end{array}$ & $40 \mu \mathrm{molg}^{-1} \mathrm{~h}^{-1}$ & [196] \\
\hline $\mathrm{Ag} @ \mathrm{C}$ sphere- $\mathrm{RuO}_{2} / \mathrm{TiO}_{2}$ & $\begin{array}{l}\text { Alkoxide hydrolysis-precipitation and facile impregnation method, EDTA-2Na }(0.5 \mathrm{~g}) \text { as a } \\
\text { sacrificial electron donor, } 300 \mathrm{~W} \text { Xe lamp, }\end{array}$ & $750 \mu \mathrm{molg}^{-1} \mathrm{~h}^{-1}$ & [197] \\
\hline $\begin{array}{l}\mathrm{IrO}_{2} \text {-loaded } \mathrm{SrTiO}_{3} \text { doped with } \mathrm{Rh} \\
\text { and } \mathrm{Sb}\end{array}$ & Conventional solid-state reaction, $\mathrm{pH}=3$, Xe lamp $300 \mathrm{~W}$ with cutoff filter $(>440 \mathrm{~nm})$ & $10 \mu \mathrm{molg}^{-1} \mathrm{~h}^{-1}$ & [198] \\
\hline $\mathrm{Pt}-\mathrm{PdS} / \mathrm{CdS}$ & $\begin{array}{l}\text { Precipitation-hydrothermal process, } 0.5 \mathrm{M} \mathrm{Na}_{2} \mathrm{SO}_{3} \text { and } 0.5 \mathrm{M} \mathrm{Na}_{2} \mathrm{~S} \text {, Xe lamp } 300 \mathrm{~W},>420 \mathrm{~nm} \text {, } \\
\text { room temperature }\end{array}$ & $83 \mathrm{mmolg}^{-1} \mathrm{~h}^{-1}$ & [199] \\
\hline $\mathrm{Pt}-\mathrm{PdS} / \mathrm{CdS}$ & Photodeposition, $0.5 \mathrm{M} \mathrm{Na}_{2} \mathrm{SO}_{3}$ and $0.5 \mathrm{M} \mathrm{Na}_{2} \mathrm{~S}$, Xe lamp $300 \mathrm{~W},>420 \mathrm{~nm}$ & $29.2 \mathrm{mmolg}^{-1} \mathrm{~h}^{-1}$ & [200] \\
\hline $\mathrm{Au}-\mathrm{Pt} / \mathrm{CaIn}_{2} \mathrm{~S}_{4}$ composite & $\begin{array}{l}\text { High-temperature sulfurization and photoreduction method, } 100 \mathrm{~mL} 0.025 \mathrm{M} \mathrm{Na}_{2} \mathrm{~S} \mathrm{Na}_{2} \mathrm{SO}_{3} \text {, Xe arc } \\
\text { lamp } 300 \mathrm{~W}, 420 \leq \lambda \leq 750 \mathrm{~nm}\end{array}$ & $11 \mathrm{mmolg}^{-1} \mathrm{~h}^{-1}$ & [201] \\
\hline Pt-Pd hybrid nano-particle on CdS & $\begin{array}{l}\text { Two-step chemical reduction, photo-induced electrons, }\left(\mathrm{NH}_{4}\right)_{2} \mathrm{SO}_{3} 1 \mathrm{M}, 283 \mathrm{~K}, 300 \mathrm{~W} \text { Xe light } \\
(\lambda>420 \mathrm{~nm})\end{array}$ & $25.28 \mathrm{mmolg}^{-1} \mathrm{~h}^{-1}$ & [202] \\
\hline AuPd nanoparticles $/ \mathrm{g}-\mathrm{C}_{3} \mathrm{~N}_{4}$ & $\begin{array}{l}\text { In situ chemical deposition method, } 100 \mathrm{~mL} \text { of } 10 \text { vol\% triethanolamine and } \mathrm{K}_{2} \mathrm{HPO}_{4} \text {, Xe lamp } 300 \\
\mathrm{UV}, \lambda \geq 400 \mathrm{~nm}, 4^{\circ} \mathrm{C}\end{array}$ & $326 \mu \mathrm{molg}^{-1} \mathrm{~h}^{-1}$ & [203] \\
\hline $\mathrm{Pt}-\mathrm{Ru} / \mathrm{Y}_{2} \mathrm{Ta}_{2} \mathrm{O}_{5} \mathrm{~N}_{2}$ & $20 \% \mathrm{v} / \mathrm{v}$ ethanol solution, Xe lamp $300 \mathrm{~W}(\lambda>420 \mathrm{~nm})$ & $833 \mu \mathrm{molg}^{-1} \mathrm{~h}^{-1}$ & [204] \\
\hline
\end{tabular}




\subsection{Noble metal sulfide}

Metal sulfide is an important type of semiconductor, where metal cation is associated with sulfur, which can be in single, double, or multiple forms. They can have special, unique, and diverse properties due to the extensive range of available metal sulfides with different structural types, which makes them eminently suitable for producing semiconductors with varied and unique properties through controlling the production processes parameters like composition control, doping, defect control, etc . Commonly reported noble metal sulfides such as $\mathrm{Ag}_{2} \mathrm{~S}$ [205] and PdS [206] as mono-metal sulfide and $\mathrm{AgInS}_{2}$ [207] and $\mathrm{AgGaS}_{2}$ [208] as bi-noble metal sulfide have been recognized.

Noble metal sulfides have clear quantum effects because their effective mass is small and they have a shallower capacitance band, long lifetime and lower redox potential than metal oxides. The charge excitation and the ability to absorb light in metal sulfides depend on these properties. The valence and conductivity bands of these materials, such as palladium sulfide, are adjustable; so many studies have been done on the conversion of photo energy by the quantum dots of these materials [209]. Since noble metal sulfides are rare or toxic compounds, they have scarcely been used in the design of photocatalysts to not conflict with the "ubiquitous element strategy" approach to building a stable and secure society [210]. The selectivity and sensitivity of metal sulfides at operating temperatures are higher than those of metal oxides [211]. However, the operating temperature required for sulfide species is lower than for metal oxides. Another distinguishing feature of metal sulfides is their lower melting point, but metal oxides still play a prominent role in photocatalytic processes. To date, numerous physical and chemical methods for the fabrication of high quality metal sulfides have been investigated to develop large-scale production with a welldefined size, shape, structure, and defect state. The strategies used to develop single-metal or bimetallic sulfide systems are shown in Fig. 9. Monometallic and bimetallic sulfides are short-term durable because they are degraded by light, so their performance is unsatisfactory for $\mathrm{H}_{2}$ production through solar power. In addition, sacrificial agents should be used to increase the photocatalytic activity of such compounds. However, the activation energy of the hydrogen production reaction can be reduced through heterojunctions [212]. To modify the electronic

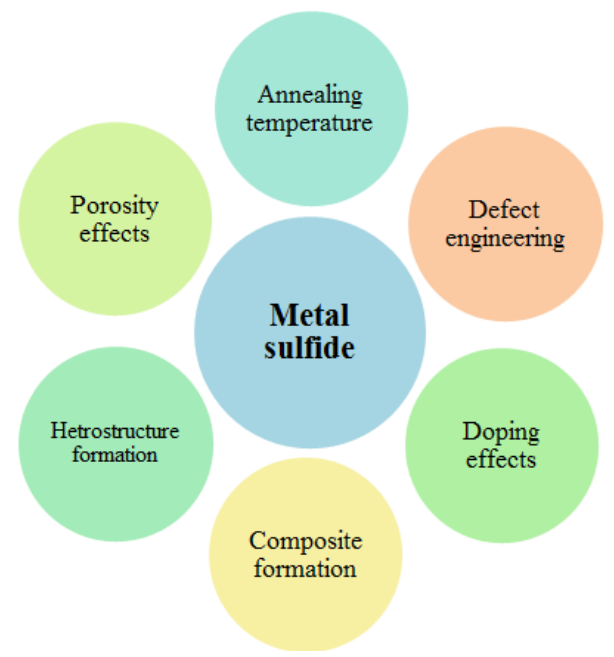

Fig. 9. Principled techniques to enhance the activity of metal sulfide systems. structure of nanoparticles, ion doping exposes more active sites and prevents recombination and aggregation of carriers. Compared with bimetal sulfide/ $/ \mathrm{TiO}_{2}$, recently developed ternary-metal-sulfide/ $/ \mathrm{TiO}_{2}$ photocatalysts have the advantages of low toxicity, a tunable band structure, and favorable chemical stability, enabling a higher photocatalytic hydrogen evolution rate [213].

In 2019 , Wu et al achieved a production rate of $5.93 \mathrm{mmolg}^{-1} \mathrm{~h}^{-1}$ hydrogen under $\mathrm{AgGaS}_{2}$ nanocrystals [214]. $\mathrm{AgGaS}_{2}$ nanocrystal has double-vacancy feature: sulfur vacancies and silver vacancies, which is controllable by only altering the molar ratio of $\mathrm{Ag}$ and $\mathrm{Ga}$ prototypes. $\mathrm{TiO}_{2} / \mathrm{AgGaS}_{2}$ [215] and $\mathrm{n}-\mathrm{CdS} / \mathrm{p}-\mathrm{AgGaS}_{2}$ [216] have also been previously used as sulfide photocatalysts in $\mathrm{Na}_{2} \mathrm{~S} / \mathrm{Na}_{2} \mathrm{SO}_{3}$ solution.

\section{Water splitting reactors}

Reactors such as membrane reactor, surface uniform concentrator (SUC), combined parabolic concentrator (CPC), column reactor, and parabolic trough concentrator (PTC) have been proposed to produce photocatalytic hydrogen by solar power [217]. Materials such as polytetrafluoroethylene, polyvinylidene fluoride, and polypropylene used in microfiltration or ultrafiltration membranes are hydrophobic in membrane reactors [218]. These materials do not meet the criteria for fouling resistance because they are prone to sediment due to their hydrophobic properties, especially biological sediment. Sediments deposit in the membranes and reduce the filtration resistance. The pores of the membrane become clogged with the accumulation of sediments, and a small flux passes through the membrane over time, reducing the life of the membrane, thus imposing additional costs on the process. Hence, sediment-degrading membranes must be constructed to overcome these problems. On the other hand, it is possible to reduce bio-sediment by using photocatalysts with pre-treatment to remove bacteria from the primary feed.

\section{Conclusions}

Photocatalytic production of hydrogen through a water-splitting reaction using sunlight is a way to compensate for fuel shortagies and provide renewable energy. So far, the main approach to the production of photocatalytic hydrogen has been the use of semiconductors, especially titania, which is far from the optimal production criteria. In general, there are four crucial roles for photocatalysts: 1) lightharvesting center, 2) act as the interface with the semiconductor to effectively catch charge carrier and encourage electron-hole pair separation, 3) they also act as efficient active sites for supplying trapped charges to redox reaction, 4) they also take effect as an alternative reaction site for supporting the photocorrosion of semiconductors. In this regard, new ways to overcome the limitations and disadvantages of photocatalysts, especially the development of light absorption, have been an attractive solution. For this purpose, the use of cocatalysts designed with noble metals (e g. Ag, Au, Pt, Ru and $\mathrm{Rh}$ ) can be a good way to separate the charges and reduce the reaction activation energy. Another advantage of noble metals is their resistance to corrosion and oxidation, which are superior to other metals. In total, four configurations have been proposed for noble metal-based cocatalysts, including single atomic noble cocatalysts, dual cocatalysts, and noble metal sulfide cocatalysts. For the photocatalytic $\mathrm{H}_{2}$ generation, the atomic substitution of noble metals on semiconductors performed better than the coating layer. Load separation and transfer of 
charge carriers have been more successful in such photocatalysts. Photocatalysts can be supported by the incorporation of noble metal oxides. But metal oxides have disadvantages such as short excited-state lifetimes, low electrical conductivity and high defect concentrations that cannot be eliminated alone. To avoid these shortcomings, new materials with triple and quaternary compounds are needed. In addition, the construction of a heterojunction semiconductor can be used to enhance charge separation and transfer. It is noteworthy that in the evolution of hydrogen, aqueous solutions are also examined. Therefore, the selection of the sacrificing agent is one of the significant parameters in the process of photocatalytic $\mathrm{H}_{2}$ evolution.

\section{References}

[1] S. O'Meara, China's plan to cut coal and boost green growth, Nature. 584 (2020) S1-S3. https://doi.org/10.1038/d41586-020-02464-5.

[2] A. Akhoondi, A.I. Osman, A. Alizadeh Eslami, Direct catalytic production of dimethyl ether from $\mathrm{CO}$ and $\mathrm{CO} 2$ : A review, Synth. Sinter. 1 (2021) 105-120. https://doi.org/10.53063/synsint.2021.1229.

[3] P.A. Owusu, S. Asumadu-Sarkodie, S. Dubey, A review of renewable energy sources, sustainability issues and climate change mitigation, Cogent Engineering. 3 (2016) 1167990. https://doi.org/10.1080/23311916.2016.1167990.

[4] A. Fujishima, K. Honda, Electrochemical Photolysis of Water at a Semiconductor Electrode, Nature. 238 (1972) 37-38. https://doi.org/10.1038/238037a0.

[5] S.I.S. Mashuri, M.L. Ibrahim, M.F. Kasim, M.S. Mastuli, et al., Photocatalysis for Organic Wastewater Treatment: From the Basis to Current Challenges for Society, 10 (2020) 1260. https://doi.org/10.3390/catal10111260.

[6] M. Patel, S. Kim, T.T. Nguyen, J. Kim, C.P. Wong, Transparent sustainable energy platform: Closed-loop energy chain of solarelectric-hydrogen by transparent photovoltaics, photo-electrochemical cells and fuel system, Nano Energy. 90 (2021) 106496. https://doi.org/10.1016/j.nanoen.2021.106496.

[7] D.L.T. Nguyen, M.A. Tekalgne, T.H.C. Nguyen, M.T.N. Dinh, et al., Recent development of high-performance photocatalysts for N2 fixation: A review, J. Environ. Chem. Eng. 9 (2021) 104997. https://doi.org/10.1016/j.jece.2020.104997.

[8] A. Kumar, V. Hasija, A. Sudhaik, P. Raizada, et al., Artificial leaf for light-driven $\mathrm{CO} 2$ reduction: Basic concepts, advanced structures and selective solar-to-chemical products, Chem. Eng. J. 430 (2022) 133031. https://doi.org/10.1016/j.cej.2021.133031.

[9] A.S.K. Kumar, J.G. You, W.B. Tseng, G.D. Dwivedi, et al., Magnetically Separable Nanospherical g-C3N4@Fe3O4 as a Recyclable Material for Chromium Adsorption and Visible-LightDriven Catalytic Reduction of Aromatic Nitro Compounds, ACS Sustain. Chem. Eng. 7 (2019) 6662-6671. https://doi.org/10.1021/acssuschemeng.8b05727.

[10] X. Wang, S. Hong, H. Lian, X. Zhan, et al., Photocatalytic degradation of surface-coated tourmaline-titanium dioxide for selfcleaning of formaldehyde emitted from furniture, J. Hazard. Mater. 420 (2021) 126565. https://doi.org/10.1016/j.jhazmat.2021.126565.

[11] F. Fresno, R. Portela, S. Suárez, J.M. Coronado, Photocatalytic materials: recent achievements and near future trends, J. Mater. Chem. 2 (2014) 2863-2884. https://doi.org/10.1039/C3TA13793G.

[12] F. Iqbal, B. Abdullah, H. Oladipo, M. Yusuf, et al., Recent developments in photocatalytic irradiation from $\mathrm{CO} 2$ to methanol, Nanostructured Photocatalysts, Elsevier. (2021) 519-540. https://doi.org/10.1016/B978-0-12-823007-7.00015-8.

[13] A. Kudo, Y. Miseki, Heterogeneous photocatalyst materials for water splitting, Chem. Soc. Rev. 38 (2009) 253-278. https://doi.org/10.1039/B800489G.

[14] A. Akhoondi, U. Feleni, B. Bethi, A.O. Idris, A. Hojjati-Najafabadi, Advances in metal-based vanadate compound photocatalysts: synthesis, properties and applications, Synth. sinter. 1 (2021) 151168. https://doi.org/10.53063/synsint.2021.1344.

[15] J. Strunk, Heterogeneous Photocatalysis: From Fundamentals to Applications in Energy Conversion and Depollution, Wiley-VCH. (2020)

[16] C.W. Huang, B.S. Nguyen, J.C.S. Wu, V.H. Nguyen, A current perspective for photocatalysis towards the hydrogen production from biomass-derived organic substances and water, Int. J. Hydrog. Energy. 45 (2020) 18144-18159. https://doi.org/10.1016/j.ijhydene.2019.08.121.

[17] K. Majrik, Z. Pászti, L. Korecz, J. Mihály, et al., Effect of the Microstructure of the Semiconductor Support on the Photocatalytic Performance of the Pt-PtOx/TiO2 Catalyst System, Materials. 14 (2021) 943. https://doi.org/10.3390/ma14040943.

[18] S.A. Kurnosenko, V.V. Voytovich, O.I. Silyukov, I.A. Rodionov, et al., Photocatalytic Activity of n-Alkylamine and n-Alkoxy Derivatives of Layered Perovskite-like Titanates H2Ln2Ti3O10 (Ln $=\mathrm{La}, \mathrm{Nd})$ in the Reaction of Hydrogen Production from an Aqueous Solution of Methanol, Catalysts. 11 (2021) 1279. https://doi.org/10.3390/catal11111279.

[19] I.R .Hamdani, A.N. Bhaskarwar, Recent progress in material selection and device designs for photoelectrochemical water-splitting, Renew. Sust. Energ. Rev. 138 (2021) 110503. https://doi.org/10.1016/j.rser.2020.110503.

[20] L. Sun, Q. Luo, Z. Dai, F. Ma, Material libraries for electrocatalytic overall water splitting, Coord. Chem. Rev. 444 (2021) 214049. https://doi.org/10.1016/j.ccr.2021.214049.

[21] R.S. Sutar, R.P. Barkul, S.D. Delekar, M.K. Patil, Sunlight assisted photocatalytic degradation of organic pollutants using g-C3N4-TiO2 nanocomposites, Arab. J. Chem. 13 (2020) 4966-4977. https://doi.org/10.1016/j.arabjc.2020.01.019.

[22] P. Raizada, T.H.C. Nguyen, S. Patial, P. Singh, et al., Toward practical solar-driven photocatalytic water splitting on twodimensional MoS2 based solid-state Z-scheme and S-scheme heterostructure, Fuel. 303 (2021) 121302. https://doi.org/10.1016/S1872-5813(21)60109-3.

[23] R. Kumar, P. Raizada, A.A. Parwaz Khan, V.H. Nguyen, Q.V. Le, et al., Recent progress in emerging BiPO4-based photocatalysts: Synthesis, properties, modification strategies, and photocatalytic applications, J. Mater. Sci. Technol. 108 (2022) 208-225. https://doi.org/10.1016/j.jmst.2021.08.053.

[24] J. Wang, F.E. Osterloh, Limiting factors for photochemical charge separation in $\mathrm{BiVO} 4 / \mathrm{Co} 3 \mathrm{O} 4$, a highly active photocatalyst for water oxidation in sunlight, J. Mater. Chem. A. 2 (2014) 9405-9411. https://doi.org/10.1039/C4TA01654H.

[25] S. Tiwari, S. Kumar, A.K. Ganguli, Role of MoS2/rGO co-catalyst to enhance the activity and stability of $\mathrm{Cu} 2 \mathrm{O}$ as photocatalyst towards photoelectrochemical water splitting, J. Photochem. Photobiol. A. 424 (2022) 113622. https://doi.org/10.1016/j.jphotochem.2021.113622.

[26] J. Li, Z. Zhao, Z. Li, H. Yang, et al., Construction of immobilized films photocatalysts with $\mathrm{CdS}$ clusters decorated by metal $\mathrm{Cd}$ and $\mathrm{BiOCl}$ for photocatalytic degradation of tetracycline antibiotics, Chin. Chem. Lett. (2021) In Press. https://doi.org/10.1016/j.cclet.2021.10.080.

[27] T. Liu, Y. Wang, P. Shan, Y. Chen, et al., Hydrogen evolution from MoSe2/WO3( $\left.\begin{array}{lll}0 & 0 & 1\end{array}\right)$ heterojunction by photocatalytic water splitting: A density functional theory study, Appl. Surface Sci. 564 (2021) 150117. https://doi.org/10.1016/j.apsusc.2021.150117.

[28] Y.C. Chang, S.Y. Syu, Z.Y. Wu, Fabrication of ZnO-In2S3 composite nanofiber as highly efficient hydrogen evolution photocatalyst, Mater. Lett. 302 (2021) 130435. https://doi.org/10.1016/j.matlet.2021.130435.

[29] K. Ji, K. Matras-Postolek, R. Shi, L. Chen, et al., MoS2/CoS2 heterostructures embedded in N-doped carbon nanosheets towards enhanced hydrogen evolution reaction, J. Alloys Compd. 891 (2022) 161962. https://doi.org/10.1016/j.jallcom.2021.161962. 
[30] T.V. Nguyen, H.H. Do, M. Tekalgne, Q.V. Le, et al., WS2-WCWO3 nano-hollow spheres as an efficient and durable catalyst for hydrogen evolution reaction, Nano Convergence. 8 (2021) 28. https://doi.org/10.1186/s40580-021-00278-3.

[31] W. Shi, M. Li, X. Huang, H. Ren, et al., Facile synthesis of 2D/2D Co3(PO4)2/g-C3N4 heterojunction for highly photocatalytic overall water splitting under visible light, Chem. Eng. J. 382 (2020) 122960. https://doi.org/10.1016/j.cej.2019.122960.

[32] K.M. Emran, S.M. Ali, TNT/LaFeO3 composite as novel condition catalyst for ameliorating hydrogen evolution reaction, Electrochem. commun. 133 (2021) 107149. https://doi.org/10.1016/j.elecom.2021.107149.

[33] M. Ismael, The photocatalytic performance of the $\mathrm{ZnO} / \mathrm{g}-\mathrm{C} 3 \mathrm{~N} 4$ composite photocatalyst toward degradation of organic pollutants and its inactivity toward hydrogen evolution: The influence of light irradiation and charge transfer, Chem. Physics Lett. 739 (2020) 136992. https://doi.org/10.1016/j.cplett.2019.136992.

[34] Y. Chen, Q. Zhao, Y. Yao, T. Li, The preparation of ionic liquid based iron phosphate/CNTs composite via microwave radiation for hydrogen evolution reaction and oxygen evolution reaction, Arab. J. Chem. 14 (2021) 103440. https://doi.org/10.1016/j.arabjc.2021.103440.

[35] L. Li, X. Wang, J. Li, Y. Guo, et al., One-pot synthesis of ultrafine Pt-decorated MoS2/N-doped carbon composite with sponge-like morphology for efficient hydrogen evolution reaction, J. Alloys Comp. 872 (2021) 159562. https://doi.org/10.1016/j.jallcom.2021.159562.

[36] C. Gao, H. Hua, M. Du, J. Liu, et al., 1T/2H MoS2 nanoflowers decorated amorphous Mo-CoSx skeleton: A ZIF-based composite electrocatalyst for the hydrogen evolution reaction, Appl. Surface Sci. 515 (2020) 145842. https://doi.org/10.1016/j.apsusc.2020.145842.

[37] J. Zhao, W. Li, S. Wu, F. Xu, et al., Strong interfacial interaction significantly improving hydrogen evolution reaction performances of MoS2/Ti4O7 composite catalysts, Electrochimica Acta. 337 (2020) 135850. https://doi.org/10.1016/j.electacta.2020.135850.

[38] S. Sun, M. Watanabe, P. Wang, T. Ishihara, Synergistic Enhancement of $\mathrm{H} 2$ and $\mathrm{CH} 4$ Evolution by $\mathrm{CO} 2$ Photoreduction in Water with Reduced Graphene Oxide-Bismuth Monoxide Quantum Dot Catalyst, ACS Appl. Energy Mater. 2 (2019) 2104-2112. https://doi.org/10.1021/acsaem.8b02153.

[39] M. Yin, J. Sun, Y. Li, Y. Ye, et al., Efficient photocatalytic hydrogen evolution over MoS2/activated carbon composite sensitized by Erythrosin B under LED light irradiation, Catal. Commun. 142 (2020) 106029. https://doi.org/10.1016/j.catcom.2020.106029.

[40] D.V. Esposito, S.T. Hunt, Y.C. Kimmel, J.G. Chen, A New Class of Electrocatalysts for Hydrogen Production from Water Electrolysis: Metal Monolayers Supported on Low-Cost Transition Metal Carbides, J. Am. Chem. Soc. 134 (2012) 3025-3033. https://doi.org/10.1021/ja208656v.

[41] Y. Li, Y.K. Peng, L. Hu, J. Zheng, et al., Photocatalytic water splitting by N-TiO2 on $\mathrm{MgO}$ (111) with exceptional quantum efficiencies at elevated temperatures, Nature Commun. 10 (2019) 4421. https://doi.org/10.1038/s41467-019-12385-1.

[42] Z. Pan, N. Pan, L. Chen, J. He, M. Zhang, Flower-like MOF-derived $\mathrm{Co}-\mathrm{N}$-doped carbon composite with remarkable activity and durability for electrochemical hydrogen evolution reaction, Int. J. Hydrog. Energy. 44 (2019) 30075-30083. https://doi.org/10.1016/j.ijhydene.2019.09.117.

[43] Y. Qin, H. Li, J. Lu, F. Meng, et al., Nitrogen-doped hydrogenated $\mathrm{TiO} 2$ modified with CdS nanorods with enhanced optical absorption, charge separation and photocatalytic hydrogen evolution, Chem. Eng. J. 384 (2020) 123275. https://doi.org/10.1016/j.cej.2019.123275.

[44] T.P. Nguyen, S.Y. Kim, T.H. Lee, H.W. Jang, et al., Facile synthesis ofW2C@WS2 alloy nanoflowers and their hydrogen generation performance, Appl. Surface Sci. 504 (2020) 144389. https://doi.org/10.1016/j.apsusc.2019.144389.
[45] Y. Yusran, H. Li, X. Guan, Q. Fang, S. Qiu, Covalent Organic Frameworks for Catalysis, EnergyChem. 2 (2020) 100035. https://doi.org/10.1016/j.enchem.2020.100035.

[46] R. Kavitha, P.M. Nithya, S. Girish Kumar, Noble metal deposited graphitic carbon nitride based heterojunction photocatalysts, Appl. Surf. Sci. 508 (2020) 145142. https://doi.org/10.1016/j.apsusc.2019.145142.

[47] M. Passi, B. Pal, A review on CaTiO3 photocatalyst: Activity enhancement methods and photocatalytic applications, Powder Technol. 388 (2021) 274-304. https://doi.org/10.1016/j.powtec.2021.04.056.

[48] C. Sun, J. Yang, M. Xu, Y. Cui, et al., Recent intensification strategies of SnO2-based photocatalysts: A review, Chem. Eng. J. 427 (2022) 131564. https://doi.org/10.1016/j.cej.2021.131564.

[49] R. Yang, Y. Zhang, Y. Fan, R. Wang, et al., InVO4-based photocatalysts for energy and environmental applications, Chem. Eng. J. 428 (2022) 131145. https://doi.org/10.1016/j.cej.2021.131145.

[50] Y. Liu, Z. Sun, Y.H. Hu, Bimetallic cocatalysts for photocatalytic hydrogen production from water, Chem. Eng. J. 409 (2021) 128250. https://doi.org/10.1016/j.cej.2020.128250.

[51] Y.R. Lin, G.V.C. Dizon, K. Yamada, C.Y. Liu, et al., Sulfur-doped g-C3N4 nanosheets for photocatalysis: Z-scheme water splitting and decreased biofouling, J. Colloid Interface Sci. 567 (2020) 202-212. https://doi.org/10.1016/j.jcis.2020.02.017.

[52] Q. Wei, Y. Yang, H. Liu, J. Hou, et al., Experimental study on direct solar photocatalytic water splitting for hydrogen production using surface uniform concentrators, Int. J. Hydrog. Energy. 43 (2018) 13745-13753. https://doi.org/10.1016/j.ijhydene.2018.01.135.

[53] C. Jiang, L. Yu, S. Yang, K. Li, A Review of the Compound Parabolic Concentrator (CPC) with a Tubular Absorber, Energies. 13 (2020) 695. https://doi.org/10.3390/en13030695.

[54] H. Derbal-Mokrane, F. Amrouche, M.N. Omari, I. Yahmi, Hydrogen production through parabolic trough power plant based on the Organic Rankine Cycle implemented in the Algerian Sahara, Int. J. Hydrog. Energy. 46 (2021) 32768-32782. https://doi.org/10.1016/j.ijhydene.2021.07.135.

[55] R. Molinari, C. Lavorato, P. Argurio, Visible-Light Photocatalysts and Their Perspectives for Building Photocatalytic Membrane Reactors for Various Liquid Phase Chemical Conversions, Catalysts. 10 (2020) 1334. https://doi.org/10.3390/catal10111334.

[56] M.Y. Qi, M. Conte, M. Anpo, Z.R. Tang, Y.J. Xu, Cooperative Coupling of Oxidative Organic Synthesis and Hydrogen Production over Semiconductor-Based Photocatalysts, Chem. Rev. 121 (2021) 13051-13085. https://doi.org/10.1021/acs.chemrev.1c00197.

[57] T. Takata, C. Pan, K. Domen, Recent progress in oxynitride photocatalysts for visible-light-driven water splitting, Sci Technol Adv Mater. 16 (2015) 033506. https://doi.org/10.1088/14686996/16/3/033506.

[58] D.I. Kondarides, V.M. Daskalaki, A. Patsoura, X.E. Verykios, Hydrogen Production by Photo-Induced Reforming of Biomass Components and Derivatives at Ambient Conditions, Catal. Lett. 122 (2008) 26-32. https://doi.org/10.1007/s10562-007-9330-3.

[59] C. Xia, T.H.C. Nguyen, X.C. Nguyen, S.Y. Kim, et al., Emerging cocatalysts in $\mathrm{TiO} 2$-based photocatalysts for light-driven catalytic hydrogen evolution: Progress and perspectives, Fuel. 307 (2022) 121745. https://doi.org/10.1016/j.fuel.2021.121745.

[60] J. Zhang, X. Wang, Solar Water Splitting at $\lambda=600 \mathrm{~nm}$ : A Step Closer to Sustainable Hydrogen Production, Angew. Chem. Int. Ed. 54 (2015) 7230-7232. https://doi.org/10.1002/anie.201502659.

[61] Q. Wang, K. Domen, Particulate Photocatalysts for Light-Driven Water Splitting: Mechanisms, Challenges, and Design Strategies, Chem. Rev. 120 (2020) 919-985. https://doi.org/10.1021/acs.chemrev.9b00201.

[62] L. Hammarström, Accumulative Charge Separation for Solar Fuels Production: Coupling Light-Induced Single Electron Transfer to 
Multielectron Catalysis, Acc. Chem. Res. 48 (2015) 840-850. https://doi.org/10.1021/ar500386x.

[63] Z. Zhang, L. Zhang, M. Nejib Hedhili, H. Zhang, P. Wang, Plasmonic Gold Nanocrystals Coupled with Photonic Crystal Seamlessly on TiO2 Nanotube Photoelectrodes for Efficient Visible Light Photoelectrochemical Water Splitting, Nano Lett. 13 (2013) 14-20. https://doi.org/10.1021/n13029202.

[64] P.A. DeSario, J.J. Pietron, D.E. DeVantier, T.H. Brintlinger, et al., Plasmonic enhancement of visible-light water splitting with $\mathrm{Au}-$ TiO2 composite aerogels, Nanoscale. 5 (2013) 8073-8083. https://doi.org/10.1039/C3NR01429K.

[65] H. Ahmad, S.K. Kamarudin, L.J. Minggu, M. Kassim, Hydrogen from photo-catalytic water splitting process: A review, Renew. Sust. Energ. Rev. 43 (2015) 599-610. https://doi.org/10.1016/j.rser.2014.10.101

[66] M. Ni, M.K.H. Leung, D.Y.C. Leung, K. Sumathy, A review and recent developments in photocatalytic water-splitting using $\mathrm{TiO} 2$ for hydrogen production, Renew. Sust. Energ. Rev. 11 (2007) 401-425. https://doi.org/10.1016/j.rser.2005.01.009.

[67] N.S. Lewis, G. Crabtree, Basic Research Needs for Solar Energy Utilization: report of the Basic Energy Sciences Workshop on Solar Energy Utilization, Renée M. Nault, Argonne National Laboratory. (2005).

[68] C. Jiang, S.J.A. Moniz, A. Wang, T. Zhang, J. Tang, Photoelectrochemical devices for solar water splitting-materials and challenges, Chem. Soc. Rev. 46 (2017) 4645-4660. https://doi.org/10.1039/C6CS00306K.

[69] X. Wei, X. He, P. Wu, F. Gong, et al., Recent advances in the design of semiconductor hollow microspheres for enhanced photocatalyticv water splitting, Int. J. Hydrog. Energy. 46 (2021) 27974-27996. https://doi.org/10.1016/j.ijhydene.2021.06.076.

[70] C. Xia, K.O. Kirlikovali, T.H.C. Nguyen, X.C. Nguyen, et al., The emerging covalent organic frameworks (COFs) for solar-driven fuels production, Coord. Chem. Rev. 446 (2021) 214117. https://doi.org/10.1016/j.ccr.2021.214117.

[71] S. Sun, W. Wang, Advanced chemical compositions and nanoarchitectures of bismuth based complex oxides for solar photocatalytic application, RSC Adv. 4 (2014) 47136-47152. https://doi.org/10.1039/C4RA06419D.

[72] X. Liu, P. Wang, X. Liang, Q. Zhang, et al., Research progress and surface/interfacial regulation methods for electrophotocatalytic hydrogen production from water splitting, materialstoday Energy. 18 (2020) 100524. https://doi.org/10.1016/j.mtener.2020.100524.

[73] S. Bai, W. Yin, L. Wang, Z. Li, Y. Xiong, Surface and interface design in cocatalysts for photocatalytic water splitting and $\mathrm{CO} 2$ reduction, RSC Advances. 6 (2016) 57446-57463. https://doi.org/10.1039/C6RA10539D.

[74] X. Li, J. Yu, M. Jaroniec, X. Chen, Cocatalysts for Selective Photoreduction of CO2 into Solar Fuels, Chem. Rev. 119 (2019) 3962-4179. https://doi.org/10.1021/acs.chemrev.8b00400.

[75] W. Jiang, S. Bai, L. Wang, X. Wang, et al., Integration of Multiple Plasmonic and Co-Catalyst Nanostructures on $\mathrm{TiO} 2$ Nanosheets for Visible-Near-Infrared Photocatalytic Hydrogen Evolution, Small. 12 (2016) 1640-8. https://doi.org/10.1002/smll.201503552.

[76] A. Tanaka, S.i Sakaguchi, K. Hashimoto, H. Kominami, Preparation of $\mathrm{Au} / \mathrm{TiO} 2$ with Metal Cocatalysts Exhibiting Strong Surface Plasmon Resonance Effective for Photoinduced Hydrogen Formation under Irradiation of Visible Light, ACS Catalysis. 3 (2013) 79-85. https://doi.org/10.1021/cs3006499.

[77] A. Tanaka, K. Nakanishi, R. Hamada, K. Hashimoto, H. Kominami, Simultaneous and Stoichiometric Water Oxidation and $\mathrm{Cr}(\mathrm{VI})$ Reduction in Aqueous Suspensions of Functionalized Plasmonic Photocatalyst Au/TiO2-Pt under Irradiation of Green Light, ACS Catalysis 3 (2013) 1886-1891. https://doi.org/10.1021/cs400433r.

[78] Z. Xu, M. Quintanilla, F. Vetrone, A.O. Govorov, et al., Harvesting Lost Photons: Plasmon and Upconversion Enhanced Broadband Photocatalytic Activity in Core@Shell Microspheres Based on
Lanthanide-Doped NaYF4, TiO2, and Au, Adv. Funct. Mater. 25 (2015) 2950-2960. https://doi.org/10.1002/adfm.201500810.

[79] A. Sudhaik, A.A. Parwaz Khan, P. Raizada, V.H. Nguyen, Q.V. Le, et al., Strategies based review on near-infrared light-driven bismuth nanocomposites for environmental pollutants degradation, Chemosphere. (2021) 132781. https://doi.org/10.1016/j.chemosphere.2021.132781.

[80] A. Gobrecht, R. Bendoula, J.M. Roger, V. Bellon-Maurel, Combining linear polarization spectroscopy and the Representative Layer Theory to measure the Beer-Lambert law absorbance of highly scattering materials, Analytica Chimica Acta. 853 (2015) 486494. https://doi.org/10.1016/j.aca.2014.10.014.

[81] F.E. Osterloh, Inorganic nanostructures for photoelectrochemical and photocatalytic water splitting, Chem. Soc. Rev. 42 (2013) 2294-2320. https://doi.org/10.1039/C2CS35266D.

[82] F. E. Osterloh, Inorganic Materials as Catalysts for Photochemical Splitting of Water, Chem. Mater. 20 (2008) 35-54. https://doi.org/10.1021/cm7024203.

[83] P.S. Bassi, Gurudayal, L.H. Wong, J. Barber, Iron based photoanodes for solar fuel production, Phys. Chem. Chem. Phys. 16 (2014) 11834-11842. https://doi.org/10.1039/C3CP55174A.

[84] H.C. Chen, C.W. Huang, J.C.S. Wu, S.T. Lin, Theoretical Investigation of the Metal-Doped $\mathrm{SrTiO} 3$ Photocatalysts for Water Splitting, J. Phys. Chem. C. 116 (2012) 7897-7903. https://doi.org/10.1021/jp300910e.

[85] S. Noothongkaew, J.K. Han, Y.B. Lee, O. Thumthan, K.S. An, Au NPs decorated $\mathrm{TiO} 2$ nanotubes array candidate for UV photodetectors, Prog. Nat. Sci. 27 (2017) 641-646. https://doi.org/10.1016/j.pnsc.2017.10.001.

[86] J.A. Ortega Méndez, Cristina R. López, E. Pulido Melián, O. González Díaz, et al., Production of hydrogen by water photosplitting over commercial and synthesised $\mathrm{Au} / \mathrm{TiO} 2$ catalysts, Appl. Catal. B. 147 (2014) 439-452.

https://doi.org/10.1016/j.apcatb.2013.09.029.

[87] X. Zhou, N. Liu, T. Yokosawa, A. Osvet, et al., Intrinsically Activated SrTiO3: Photocatalytic H2 Evolution from Neutral Aqueous Methanol Solution in the Absence of Any Noble Metal Cocatalyst, ACS Appl. Mater. Interfaces. 10 (2018) 29532-29542. https://doi.org/10.1021/acsami.8b08564.

[88] Y. Fan, Y. Liu, H. Cui, W. Wang, et al., Photocatalytic Overall Water Splitting by $\mathrm{SrTiO} 3$ with Surface Oxygen Vacancies, Nanomaterials. 10 (2020) 2572. https://doi.org/10.3390/nano10122572.

[89] P. Shen, J.C. LofaroJr., W.R. Woerner, M.G. White, D. Su, et al., Photocatalytic activity of hydrogen evolution over Rh doped $\mathrm{SrTiO}_{3}$ prepared by polymerizable complex method, Chem. Eng. 223 (2013) 200-208. https://doi.org/10.1016/j.cej.2013.03.030.

[90] Q. Wang, T. Hisatomi, S.S. Khine Ma, Y. Li, K. Domen, Core/Shell Structured La- and Rh-Codoped $\mathrm{SrTiO} 3$ as a Hydrogen Evolution Photocatalyst in Z-Scheme Overall Water Splitting under Visible Light Irradiation, Chem. Mater. 26 (2014) 4144-4150. https://doi.org/10.1021/cm5011983.

[91] Y. Qin, F. Fang, Z. Xie, H. Lin, et al., La,Al-Codoped $\mathrm{SrTiO3}$ as a Photocatalyst in Overall Water Splitting: Significant Surface Engineering Effects on Defect Engineering, ACS Catal. 11 (2021) 11429-11439. https://doi.org/10.1021/acscatal.1c02874.

[92] T.K. Townsend, N.D. Browning, F.E. Osterloh, Nanoscale strontium titanate photocatalysts for overall water splitting, ACS Nano. 6 (2012) 7420-6. https://doi.org/10.1021/nn302647u.

[93] T.K. Townsend, N.D. Browning, F.E. Osterloh, Overall photocatalytic water splitting with $\mathrm{NiOx}-\mathrm{SrTiO3}-$ a revised mechanism, Energy Environ. Sci. 5 (2012) 9543-9550. https://doi.org/10.1039/C2EE22665K.

[94] Y. Fo, M. Wang, Y. Ma, H. Dong, X. Zhou, Origin of highly efficient photocatalyst $\mathrm{NiO} / \mathrm{SrTiO} 3$ for overall water splitting: Insights from density functional theory calculations, J. Solid State 
Chem. 292 (2020) 121683.

https://doi.org/10.1016/j.jssc.2020.121683.

[95] K.M. Macounová, R. Nebel, M. Klusáčková, M. Klementová, P. Krtil, Selectivity Control of the Photo-Catalytic Water Oxidation on SrTiO3 Nanocubes via Surface Dimensionality, ACS Appl. Mater. Interfaces. 11 (2019) 16506-16516. https://doi.org/10.1021/acsami.9b00342.

[96] V.H. Nguyen, H.H. Do, T.V. Nguyen, P. Singh, et al., Perovskite oxide-based photocatalysts for solar-driven hydrogen production: Progress and perspectives, Solar Energy. 211 (2020) 584-599. https://doi.org/10.1016/j.solener.2020.09.078.

[97] Q. Kuang, S. Yang, Template Synthesis of Single-Crystal-Like Porous SrTiO3 Nanocube Assemblies and Their Enhanced Photocatalytic Hydrogen Evolution, ACS Appl. Mater. Interfaces. 5 (2013) 3683-3690. https://doi.org/10.1021/am400254n.

[98] J. Yu, L. Qi, M. Jaroniec, Hydrogen Production by Photocatalytic Water Splitting over Pt/TiO2 Nanosheets with Exposed (001) Facets, J. Phys. Chem. C. 114 (2010) 13118-13125. https://oi.org/10.1021/jp104488b.

[99] T. Wei, Y. Zhu, Y. Wu, X. An, L.M. Liu, Effect of Single-Atom Cocatalysts on the Activity of Faceted TiO2 Photocatalysts, Langmuir. 35 (2019) 391-397. https://doi.org/10.1021/acs.langmuir.8b03488.

[100] Y. Chen, S. Ji, W. Sun, Y. Lei, et al., Engineering the Atomic Interface with Single Platinum Atoms for Enhanced Photocatalytic Hydrogen Production, Angew. Chem. Int. Ed. 59 (2020) 1295-1301. https://doi.org/10.1002/anie.201912439.

[101] S. Ida, N. Kim, E. Ertekin, S. Takenaka, T. Ishihara, Photocatalytic Reaction Centers in Two-Dimensional Titanium Oxide Crystals, J. Am. Chem. Soc. 137 (2015) 239-244. https://doi.org/10.1021/ja509970z.

[102] S. Berdyugin, E. Kozlova, A. Kurenkova, E. Gerasimov, et al., Hydrogarnet-derived $\mathrm{Rh} / \mathrm{TiO} 2$ catalysts with a low rhodium content for a photocatalytic hydrogen production, Mater. Lett. 307 (2022) 130997. https://doi.org/10.1016/j.matlet.2021.130997.

[103] S. Fang, Y. Liu, Z. Sun, J. Lang, et al., Photocatalytic hydrogen production over Rh-loaded $\mathrm{TiO} 2$ : What is the origin of hydrogen and how to achieve hydrogen production from water?, Appl. Catal. B. 278 (2020) 119316. https://doi.org/10.1016/j.apcatb.2020.119316.

[104] A. Wang, J. Li, T. Zhang, Heterogeneous single-atom catalysis, Nature Rev. Chem. 2 (2018) pages65-81.

https://oi.org/10.1038/s41570-018-0010-1.

[105] H. Zhang, S. Zuo, M. Qiu, S. Wang, et al., Direct probing of atomically dispersed $\mathrm{Ru}$ species over multi-edged $\mathrm{TiO} 2$ for highly efficient photocatalytic hydrogen evolution, Sci Adv. 6 (2020). https://doi.org/10.1126/sciadv.abb9823.

[106] Y. Okamoto, S. Ida, J. Hyodo, H. Hagiwara, T. Ishihara, Synthesis and Photocatalytic Activity of Rhodium-Doped Calcium Niobate Nanosheets for Hydrogen Production from a Water/Methanol System without Cocatalyst Loading, J. Am. Chem. Soc. 133 (2011) 18034-18037. https://doi.org/10.1021/ja207103j.

[107] S. Nishioka, K. Maeda, Hydrothermal synthesis of rhodiumdoped barium titanate nanocrystals for enhanced photocatalytic hydrogen evolution under visible light, RSC Adv. 5 (2015) 100123 100128. https://doi.org/10.1039/C5RA20044J.

[108] T.H. Chiang, G. Viswanath, Y.S. Chen, Effects of RhCrOx Cocatalyst Loaded on Different Metal Doped LaFeO3 Perovskites with Photocatalytic Hydrogen Performance under Visible Light Irradiation, Catalysts. 11 (2021) 612. https://doi.org/10.3390/catal11050612.

[109] A. Alzahrani, D. Barbash, A. Samokhvalov, "One-Pot" Synthesis and Photocatalytic Hydrogen Generation with Nanocrystalline $\mathrm{Ag}(0) / \mathrm{CaTiO} 3$ and in Situ Mechanistic Studies, The J. Phys. Chem. C. 120 (2016) 19970-19979. https://doi.org/10.1021/acs.jpcc.6b05407.

[110] S.J.P. Varapragasam, S. Mia, C. Wieting, C. Balasanthiran, et al., Ag-TiO2 Hybrid Nanocrystal Photocatalyst: Hydrogen
Evolution under UV Irradiation but Not under Visible-Light Irradiation, ACS Appl. Energy Mater. 2 (2019) 8274-8282. https://doi.org/10.1021/acsaem.9b01730.

[111] M. Shang, H. Hou, F. Gao, L. Wang, W. Yang, Mesoporous Ag@TiO2 nanofibers and their photocatalytic activity for hydrogen evolution, RSC Adv. 7 (2017) 30051-30059. https://doi.org/10.1039/C7RA03177G.

[112] D. Gao, W. Liu, Y. Xu, P. Wang, et al., Core-shell Ag@Ni cocatalyst on the $\mathrm{TiO} 2$ photocatalyst: One-step photoinduced deposition and its improved H2-evolution activity, Appl. Catal. B: Environ. 260 (2020) 118190. https://doi.org/10.1016/j.apcatb.2019.118190.

[113] B. Antil, L. Kumar, R. Ranjan, S. Shenoy, et al., OneDimensional Multichannel g-C3N4.7 Nanostructure Realizing an Efficient Photocatalytic Hydrogen Evolution Reaction and Its Theoretical Investigations, ACS Appl. Energy Mater. 4 (2021) 3118-3129. https://doi.org/10.1021/acsaem.0c02858.

[114] S.S. Lam, V.H. Nguyen, M.T. Nguyen Dinh, D.Q. Khieu, et al., Mainstream avenues for boosting graphitic carbon nitride efficiency: towards enhanced solar light-driven photocatalytic hydrogen production and environmental remediation, J. Mater. Chem. A., 8 (2020) 10571-10603. https://doi.org/10.1039/D0TA02582H.

[115] R. Liu, Z. Chen, Y. Yao, Y. Li, et al., Recent advancements in g-C3N4-based photocatalysts for photocatalytic CO2 reduction: a mini review, RSC Adv. 10 (2020) 29408-29418. https://doi.org/10.1039/D0RA05779G.

[116] J. Qin, H. Zeng, Photocatalysts fabricated by depositing plasmonic Ag nanoparticles on carbon quantum dots/graphitic carbon nitride for broad spectrum photocatalytic hydrogen generation, Appl. Catal. B. 209 (2017) 161-173. https://doi.org/10.1016/j.apcatb.2017.03.005.

[117] Y. Zhu, T. Wang, T. Xu, Y. Li, C. Wang, Size effect of Pt cocatalyst on photocatalytic efficiency of g-C3N4 for hydrogen evolution, Appl. Surf. Sci. 464 (2019) 36-42. https://doi.org/10.1016/j.apsusc.2018.09.061.

[118] K. Mori, R. Osaka, K. Naka, D. Tatsumi, H. Yamashita, UltraLow Loading of Ru Clusters over Graphitic Carbon Nitride: A Drastic Enhancement in Photocatalytic Hydrogen Evolution Activity, ChemCatChem. 11 (2019) 1963. https://doi.org/10.1002/cctc.201900073.

[119] T. Tong, B. Zhu, C. Jiang, B. Cheng, J. Yu, Mechanistic insight into the enhanced photocatalytic activity of single-atom Pt, Pd or Au-embedded g-C3N4, Appl. Surf. Sci. 433 (2018) 1175-1183. https://doi.org/10.1016/j.apsusc.2017.10.120.

[120] F. Raziq, M. Humayun, A. Ali, T. Wang, et al., Synthesis of SDoped porous g-C3N4 by using ionic liquids and subsequently coupled with $\mathrm{Au}-\mathrm{TiO} 2$ for exceptional cocatalyst-free visible-light catalytic activities, Appl. Catal. B. 237 (2018) 1082-1090. https://doi.org/10.1016/j.apcatb.2018.06.009.

[121] Q. Zhu, Z. Xu, B. Qiu, M. Xing, J. Zhang, Emerging Cocatalysts on g-C3N4 for Photocatalytic Hydrogen Evolution, Smal. 17 (2021) 2101070. https://doi.org/10.1002/smll.202101070.

[122] X. She, J. Wu, J. Zhong, H. Xu, et al., Oxygenated monolayer carbon nitride for excellent photocatalytic hydrogen evolution and external quantum efficiency, Nano Energy. 27 (2016) 138-146. https://doi.org/10.1016/j.nanoen.2016.06.042.

[123] X. Hu, R.-t Guo, L.-f. Hong, X.-f. Ji, W.-g. Pan, Recent Progress in Quantum Dots Modified g-C3N4-based Composite Photocatalysts, ChemistrySelect. 6 (2021) 10854. https://doi.org/10.1002/slct.202102952.

[124] B. Rhimi, C. Wang, D.W. Bahnemann, Latest progress in gC3N4 based heterojunctions for hydrogen production via photocatalytic water splitting: a mini review, J. Phys. Energy. 2 (2020) 042003. https://doi.org/10.1088/2515-7655/abb782.

[125] X. Liang, J. Zhao, T. Wang, Z. Zhang, et al., Constructing a ZScheme Heterojunction Photocatalyst of GaPO $4 / \alpha-\mathrm{MoC} / \mathrm{Ga} 2 \mathrm{O} 3$ without Mingling Type-II Heterojunction for CO 2 Reduction to CO, 
ACS Appl. Mater. Interfaces. 13 (2021) 33034-33044. https://oi.org/10.1021/acsami.1c07757.

[126] F. Opoku, K.K. Govender, C.G. Catharina Elizabeth van Sittert, P.P. Govender, Recent Progress in the Development of Semiconductor-Based Photocatalyst Materials for Applications in Photocatalytic Water Splitting and Degradation of Pollutants, Adv. Sustainable Syst.1 (2017) 1700006. https://doi.org/10.1002/adsu.201700006.

[127] L. Yuliati, J.H. Yang, X. Wang, K. Maeda, et al., Highly active tantalum(v) nitridenanoparticles prepared from a mesoporous carbon nitride template for photocatalytic hydrogen evolution under visible light irradiation, J. Mater. Chem. 20 (2010) 4295-4298. https://doi.org/10.1039/C0JM00341G.

[128] S. Chen, Y. Qi, Q. Ding, Z. Li. et al., Magnesia interface nanolayer modification of $\mathrm{Pt} / \mathrm{Ta} 3 \mathrm{~N} 5$ for promoted photocatalytic hydrogen production under visible light irradiation, J. Catal. 339 (2016) 77-83. https://doi.org/10.1016/j.jcat.2016.03.024.

[129] Y. Ma, K. Zhou, H. Dong, X. Zhou, Effects of Adsorbing Noble Metal Single Atoms on the Electronic Structure and Photocatalytic Activity of Ta3N5, J. Phys. Chem. C. 125 (2021) 17600-17611. https://doi.org/10.1021/acs.jpcc.1c04054.

[130] J. Ran, J. Zhang, J. Yu, M. Jaroniec, S.Z. Qiao, Earth-abundant cocatalysts for semiconductor-based photocatalytic water splitting, Chem. Soc. Rev. 43 (2014) 7787-7812. https://doi.org/10.1039/C3CS60425J.

[131] D. Wang, Y. Peng, Q. Wang, N. Pan, et al., High-efficient photo-electron transport channel in SiC constructed by depositing cocatalysts selectively on specific surface sites for visible-light $\mathrm{H} 2$ production, Appl. Phys. Lett. 108 (2016) 161601. https://doi.org/10.1063/1.4947196.

[132] D. Wang, W. Wang, Q. Wang, Z. Guo, W. Yuan, Spatial separation of Pt and $\mathrm{IrO} 2$ cocatalysts on SiC surface for enhanced photocatalysis, Mater. Lett. 201 (2017) 114-117. https://doi.org/10.1016/j.matlet.2017.04.140.

[133] M. Wang, J. Chen, X. Liao, Z. Liu, et al., Highly efficient photocatalytic hydrogen production of platinum nanoparticledecorated $\mathrm{SiC}$ nanowires under simulated sunlight irradiation, Int. J. Hydrog. Energy. 39 (2014) 14581-14587. https://doi.org/10.1016/j.ijhydene.2014.07.068.

[134] S. Shen, X. Chen, F. Ren, C.X. Kronawitter, et al., Solar lightdriven photocatalytic hydrogen evolution over ZnIn2S4 loaded with transition-metal sulfides, Nanoscale Res. Lett. 6 (2011) 290. https://doi.org/10.1186/1556-276X-6-290.

[135] Y. Chen, Y. Liu, Z. Ma, g-C3N4 Sensitized by an Indoline Dye for Photocatalytic H2 Evolution, Processes. 9 (2021) 1055. https://doi.org/10.3390/pr9061055.

[136] Z. Mo, H. Xu, X. She, Y. Song, et al., Constructing Pd/2DC3N4 composites for efficient photocatalytic $\mathrm{H} 2$ evolution through nonplasmon-induced bound electrons, Appl. Surf. Sci. 467-468 (2019) 151-157. https://doi.org/10.1016/j.apsusc.2018.10.115.

[137] X. Cai, L. Mao, M. Fujitsuka, T. Majima, et al., Effects of Bidopant and co-catalysts upon hole surface trapping on La2Ti2O7 nanosheet photocatalysts in overall solar water splitting, Nano Res. 15 (2022) 438-445. https://doi.org/10.1007/s12274-021-3498-5.

[138] G. Zhu, H. Yin, C. Yang, H. Cui, et al., Black Titania for Superior Photocatalytic Hydrogen Production and Photoelectrochemical Water Splitting, ChemCatChem. 7 (2015) 2614-2619. https://doi.org/10.1002/cctc.201500488.

[139] M.G. Méndez-Medrano, E. Kowalska, A. Lehoux, A. Herissan, et al., Surface Modification of $\mathrm{TiO} 2$ with Au Nanoclusters for Efficient Water Treatment and Hydrogen Generation under Visible Light, J. Phys. Chem. C. 120 (2016) 25010-25022. https://doi.org/10.1021/acs.jpcc.6b06854.

[140] X. Yang, X. Wu, J. Li, Y. Liu, TiO2-Au composite nanofibers for photocatalytic hydrogen evolution, RSC Adv. 9 (2019) 29097 29104. https://doi.org/10.1039/C9RA05113A.
[141] P. Jiménez-Calvo, V. Caps, M.N. Ghazzal, C. Colbeau-Justin, V. Keller, $\mathrm{Au} / \mathrm{TiO} 2(\mathrm{P} 25)-\mathrm{gC} 3 \mathrm{~N} 4$ composites with low gC3N4 content enhance $\mathrm{TiO} 2$ sensitization for remarkable $\mathrm{H} 2$ production from water under visible-light irradiation, Nano Energy. 75 (2020) 104888. https://doi.org/10.1016/j.nanoen.2020.104888.

[142] C. Marchal, T. Cottineau, M.G. Méndez-Medrano, C. ColbeauJustin, et al., Au/TiO2-gC3N4 Nanocomposites for Enhanced Photocatalytic H2 Production from Water under Visible Light Irradiation with Very Low Quantities of Sacrificial Agents, Adv. Energy Mater. 8 (2016) 1702142. https://doi.org/10.1002/aenm.201702142.

[143] M. Song, Y. Wu, G. Zheng, C. Du, Y. Su, Junction of porous gC3N4 with BiVO4 using Au as electron shuttle for cocatalyst-free robust photocatalytic hydrogen evolution, Appl. Surf. Sci. 498 (2019) 143808. https://doi.org/10.1016/j.apsusc.2019.143808.

[144] J.E. Ramos-Sanchez, R. Camposeco, S.W. Lee, V. RodríguezGonzález, Sustainable synthesis of AgNPs/strontium-titanateperovskite-like catalysts for the photocatalytic production of hydrogen, Catal. Today. 341 (2020) 112-119. https://doi.org/10.1016/j.cattod.2019.08.020.

[145] W. Soontornchaiyakul, T. Fujimura, N. Yano, Y. Kataoka, R. Sasai, Photocatalytic Hydrogen Evolution over Exfoliated Rh-Doped Titanate Nanosheets, ACS Omega. 5 (2020) 9929-9936. https://doi.org/10.1021/acsomega.0c00204.

[146] Y. Chen, S. Zhao, X. Wang, Q. Peng, et al., Synergetic Integration of Cu1.94S-ZnxCd1-xS Heteronanorods for Enhanced Visible-Light-Driven Photocatalytic Hydrogen Production, J. Am. Chem. Soc. 2016 (138) 4286-4289.

https://doi.org/10.1021/jacs.5b12666.

[147] Z. Wang, C. Yang, T. Lin, H. Yin, et al., H-Doped Black Titania with Very High Solar Absorption and Excellent Photocatalysis Enhanced by Localized Surface Plasmon Resonance, Adv. Funct. Mater. 23 (2013) 5444-5450. https://doi.org/10.1002/adfm.201300486.

[148] N. Güy, Directional transfer of photocarriers on CdS/g-C3N4 heterojunction modified with $\mathrm{Pd}$ as a cocatalyst for synergistically enhanced photocatalytic hydrogen production, Appl. Surf. Sci. 522 (2020) 146442. https://doi.org/10.1016/j.apsusc.2020.146442.

[149] J. Zhang, Z. Yu, Z. Gao, H. Ge, et al., Porous TiO2 Nanotubes with Spatially Separated Platinum and CoOx Cocatalysts Produced by Atomic Layer Deposition for Photocatalytic Hydrogen Production, Angew. Chem. Int. Ed. 56 (2017) 816. https://doi.org/10.1002/anie.201611137.

[150] H. Kadowaki, N. Saito, H. Nishiyama, Y. Inoue, RuO2-loaded $\mathrm{Sr} 2+$-doped $\mathrm{CeO} 2$ with d0 Electronic Configuration as a New Photocatalyst for Overall Water Splitting, Chem. Lett. 36 (2007) 440. https://doi.org/10.1246/cl.2007.440.

[151] Y. Yuan, J. Zheng, X. Zhang, Z. Li, et al., BaCeO3 as a novel photocatalyst with $4 \mathrm{f}$ electronic configuration for water splitting, Solid State Ionics. 178 (2008) 1711-1713. https://doi.org/10.1016/j.ssi.2007.11.012.

[152] J. Sato, H. Kobayashi, K. Ikarashi, N. Saito, H. Nishiyama, Y. Inoue, Photocatalytic Activity for Water Decomposition of RuO2Dispersed Zn2GeO4 with d10 Configuration, J. Phys. Chem. B. 108 (2004) 4369-4375. https://doi.org/10.1021/jp0373189.

[153] J. Yu, Y. Yu, P. Zhou, W. Xiao, B. Cheng, Morphologydependent photocatalytic H2-production activity of CdS, Applied Catal. B: Environ. 156-157 (2014) 184-191. https://doi.org/10.1016/j.apcatb.2014.03.013.

[154] Z.U. Rahman, N. Wei, M. Feng, D. Wang, TiO2 hollow spheres with separated $\mathrm{Au}$ and $\mathrm{RuO} 2$ co-catalysts for efficient photocatalytic water splitting, Int. J. Hydrog. Energy. 44 (2019) 13221-13231. https://doi.org/10.1016/j.ijhydene.2019.03.176.

[155] R.K. Chava, J. Yeon Do, M. Kang, Fabrication of CdS-Ag3PO4 heteronanostructures for improved visible photocatalytic hydrogen evolution, J. Alloys Compd. 727 (2017) 86-93. https://doi.org/10.1016/j.jallcom.2017.08.108. 
[156] H. Li, X. Cui, A hydrothermal route for constructing reduced graphene oxide/TiO2 nanocomposites: Enhanced photocatalytic activity for hydrogen evolution, Int. J. Hydrog. Energy. 39 (2014) 19877-19886. https://doi.org/10.1016/j.ijhydene.2014.10.010.

[157] Y. Wang, J. Yu, W. Xiao, Q. Li, Microwave-assisted hydrothermal synthesis of graphene based $\mathrm{Au}-\mathrm{TiO} 2$ photocatalysts for efficient visible-light hydrogen production, J. Mater. Chem. A. 2 (2014) 3847-3855. https://doi.org/10.1039/C3TA14908K.

[158] P. Dong, Y. Wang, A. Zhang, T. Cheng, et al., Platinum Single Atoms Anchored on a Covalent Organic Framework: Boosting Active Sites for Photocatalytic Hydrogen Evolution, ACS Catal. 11 (2021) 13266-13279. https://doi.org/10.1021/acscatal.1c03441.

[159] E. Can, B. Uralcan, R. Yildirim, Enhancing Charge Transfer in Photocatalytic Hydrogen Production over Dye-Sensitized Pt/TiO2 by Ionic Liquid Coating, ACS Appl. Energy Mater. 4 (2021) 1093110939. https://doi.org/10.1021/acsaem.1c01553.

[160] C. Ru, T. Zhou, J. Zhang, X. Wu, et al., Introducing Secondary Acceptors into Conjugated Polymers to Improve Photocatalytic Hydrogen Evolution, Macromolecules 54 (2021) 8839-8848. https://doi.org/10.1021/acs.macromol.1c00705.

[161] R. Pan, M. Hu, J. Liu, D. Li, et al., Two-Dimensional All-inOne Sulfide Monolayers Driving Photocatalytic Overall Water Splitting, Nano Lett. 21 (2021) 6228-6236. https://doi.org/10.1021/acs.nanolett.1c02008.

[162] M. Manikandan, T. Tanabe, P. Li, S. Ueda, et al., Photocatalytic Water Splitting under Visible Light by Mixed-Valence Sn3O4, ACS Appl. Mater. Interfaces. 6 (2014) 3790-3793. https://doi.org/10.1021/am500157u.

[163] J.W. Hong, Development of Visible-Light-Driven Rh-TiO2$\mathrm{CeO} 2$ Hybrid Photocatalysts for Hydrogen Production, Catalysts. 11 (2021) 848. https://doi.org/10.3390/catal11070848.

[164] S.W. Cao, J. Fang, M.M. Shahjamali, F.Y.C. Boey, et al., Plasmon-Enhanced Hydrogen Evolution on Au-InVO4 Hybrid Microspheres, RSC Adv. 2 (2012) 5513-5515. https://doi.org/10.1039/C2RA20405C.

[165] C.F. Liu, T.P. Perng, Fabrication and band structure of Ag3PO4-TiO2 heterojunction with enhanced photocatalytic hydrogen evolution, Int. J. Hydrog. Energy. 45 (2020) 149-159. https://doi.org/10.1016/j.ijhydene.2019.10.182.

[166] W. Fang, S. Yao, L. Wang, C. Li, Enhanced photocatalytic overall water splitting via hollow structure $\mathrm{Pt} / \mathrm{g}-\mathrm{C} 3 \mathrm{~N} 4 / \mathrm{BiOBr}$ photocatalyst with S-scheme heterojunction, J. Alloys Compd. 891 (2022) 162081. https://doi.org/10.1016/j.jallcom.2021.162081.

[167] M. Tabata, K. Maeda, T. Ishihara, T. Minegishi, et al., Photocatalytic Hydrogen Evolution from Water Using Copper Gallium Sulfide under Visible-Light Irradiation, J. Phys. Chem. C. 114 (2010) 11215-11220. https://doi.org/10.1021/jp103158f.

[168] K. Maeda, K. Teramura, D. Lu, N. Saito, et al., NobleMetal/Cr2O3 Core/Shell Nanoparticles as a Cocatalyst for Photocatalytic Overall Water Splitting, Angewandte Chemie Int. 45 (2006) 7806-7809. https://doi.org/10.1002/anie.200602473.

[169] M. Wang, P. Ju, W. Li, Y. Zhao, X. Han, Ag2S nanoparticledecorated MoS2 for enhanced electrocatalytic and photoelectrocatalytic activity in water splitting, Dalton Trans. 46 (2017) 483-490. https://doi.org/10.1039/C6DT04079A.

[170] L. Bai, X. Cai, J. Lu, L. Li, et al., Surface and Interface Engineering in Ag2S@MoS2 Core-Shell Nanowire Heterojunctions for Enhanced Visible Photocatalytic Hydrogen Production, ChemCatChem. 10 (2018) 2107-2114. https://doi.org/10.1002/cctc.201701998.

[171] Q. Chen, C. Suo, S. Zhang, Y. Wang, Effect of PdS on Photocatalytic Hydrogen Evolution of Nanostructured CdS under Visible Light Irradiation, Int. J. Photoenergy. (2013). https://doi.org/10.1155/2013/149586.

[172] Y.S. Lai, C.H. Yang, J.M. Jehng, The formation of (NH4)2V6O16 phase in the synthesized InVO4 for the hydrogen evolving applications, Catal. Commun. 103 (2018) 19-23. https://doi.org/10.1016/j.catcom.2017.09.008.

[173] Z. Xu, M.G. Kibria, B. AlOtaibi, P.N. Duchesne, et al., Towards enhancing photocatalytic hydrogen generation: Which is more important, alloy synergistic effect or plasmonic effect?, Appl. Catal. B. 221 (2018) 77-85. https://doi.org/10.1016/j.apcatb.2017.08.085.

[174] H. An, M. Li, R. Liu, Z. Gao, Z. Yin, Design of AgxAu1-x alloy/ZnIn2S4 system with tunable spectral response and Schottky barrier height for visible-light-driven hydrogen evolution, Chem. Eng. J. 382 (2020) 122953. https://doi.org/10.1016/j.cej.2019.122953.

[175] L. Cheng, Y. Li, A. Chen, Y. Zhu, C. Li, Subnano-Sized Pt-Au Alloyed Clusters as Enhanced Cocatalyst for Photocatalytic Hydrogen Evolution, Chem. an asian Jour. 14 (2019) 2112-2115. https://doi.org/10.1002/asia.201900453.

[176] E. Redina, A. Greish, R. Novikov, A. Strelkova, et al., $\mathrm{Au} / \mathrm{Pt} / \mathrm{TiO} 2$ catalysts prepared by redox method for the chemoselective 1,2-propanediol oxidation to lactic acid and an NMR spectroscopy approach for analyzing the product mixture, Appl. Catal. A. 491 (2015) 170-183.

https://doi.org/10.1016/j.apcata.2014.11.039.

[177] C. Xu, W. Yang, Q. Guo, D. Dai, et al., Molecular Hydrogen Formation from Photocatalysis of Methanol on Anatase-TiO2(101), J. Am. Chem. Soc. 136 (2014) 602-605. https://doi.org/10.1021/ja411020t.

[178] J. Wang, J. Zhao, F.E. Osterloh, Photochemical charge transfer observed in nanoscale hydrogen evolving photocatalysts using surface photovoltage spectroscopy, Energy Environ. Sci. 8 (2015) 2970-2976. https://doi.org/10.1039/C5EE01701G.

[179] Q. Wang, T. Hisatomi, Q. Jia, H. Tokudome, et al., Scalable water splitting on particulate photocatalyst sheets with a solar-tohydrogen energy conversion efficiency exceeding $1 \%$, nature mater. 15 (2016) 611-615. https://doi.org/10.1038/nmat4589.

[180] N. Xiao, S. Li, S. Liu, B. Xu, et al., Novel PtPd alloy nanoparticle-decorated g-C $3 \mathrm{~N} 4$ nanosheets with enhanced photocatalytic activity for $\mathrm{H} 2$ evolution under visible light irradiation, Chin. J. Catal. 40 (2019) 352-361. https://doi.org/10.1016/S18722067(18)63180-8.

[181] U. Caudillo-Flores, M.J. Muñoz-Batista, M. Fernández-García, A. Kubacka, Bimetallic Pt-Pd co-catalyst Nb-doped TiO2 materials for $\mathrm{H} 2$ photo-production under UV and Visible light illumination, Appl. Catal. B. 238 (2018) 533-545. https://doi.org/10.1016/j.apcatb.2018.07.047.

[182] S. Bai, L. Yang, C. Wang, Y. Lin, et al., Boosting Photocatalytic Water Splitting: Interfacial Charge Polarization in Atomically Controlled Core-Shell Cocatalysts, Angew. Chem. Int. Ed. 54 (2015) 14810-14814. https://doi.org/10.1002/anie.201508024.

[183] T. Su, Q. Shao, Z. Qin, Z. Guo, et al., Role of Interfaces in Two-Dimensional Photocatalyst for Water Splitting, ACS Catal. 8 (2018) 2253-2276. https://doi.org/10.1021/acscatal.7b03437.

[184] Y. Sun, S. Gao, F. Lei, Y. Xie, Atomically-thin twodimensional sheets for understanding active sites in catalysis, Chem. Soc. Rev. 44 (2015) 623-636. https://doi.org/10.1039/C4CS00236A.

[185] P. Niu, L. Zhang, G. Liu, H.M. Cheng, Graphene-Like Carbon Nitride Nanosheets for Improved Photocatalytic Activities, Adv. Funct. Mater. 22 (2012) 4763-4770. https://doi.org/10.1002/adfm.201200922.

[186] S. Kouser, A. Thannikoth, U. Gupta, U.V. Waghmare, C.N.R. Rao, 2D-GaS as a Photocatalyst for Water Splitting to Produce H2, Small. 11 (2015) 4723-4730. https://doi.org/10.1002/smll.201501077.

[187] S. Liang, Y. Xia, S. Zhu, S. Zheng, et al., Au and Pt co-loaded g-C3N4 nanosheets for enhanced photocatalytic hydrogen production under visible light irradiation, Appl. Surf. Sci. 358 (2015) 304-312. https://doi.org/10.1016/j.apsusc.2015.08.035.

[188] K. Bhunia, M. Chandra, S. Khilari, D. Pradhan, Bimetallic PtAu Alloy Nanoparticles-Integrated g-C3N4 Hybrid as an Efficient Photocatalyst for Water-to-Hydrogen Conversion, ACS Appl. Mater. 
Interfaces. 11 (2019) 478-488.

https://doi.org/10.1021/acsami.8b12183.

[189] B. Pongthawornsakun, O. Mekasuwandumrong, S, Prakash, E. Ehret, et al., Effect of reduction temperature on the characteristics and catalytic properties of $\mathrm{TiO} 2$ supported AuPd alloy particles prepared by one-step flame spray pyrolysis in the selective hydrogenation of 1-heptyne, Appl. Catal. A. 506 (2015) 278-287. https://doi.org/10.1016/j.apcata.2015.09.012.

[190] Q. Jia, A. Iwase, A. Kudo, BiVO4-Ru/SrTiO3:Rh composite Zscheme photocatalyst for solar water splitting, Chem. Sci. 5 (2014) 1513-1519. https://doi.org/10.1039/C3SC52810C.

[191] B. Li, Q. Li, B. Gupta, C. He, J. Yang, Boosting visible-lightdriven catalytic hydrogen evolution via surface Ti3+ and bulk oxygen vacancies in urchin-like hollow black $\mathrm{TiO} 2$ decorated with RuO2 and Pt dual cocatalysts, Catal. Sci. Technol. 10 (2020) 7914. https://doi.org/10.1039/D0CY01706J.

[192] Y. Ma, R. Chong, F. Zhang, Q. Xu, et al., Synergetic effect of dual cocatalysts in photocatalytic $\mathrm{H} 2$ production on $\mathrm{Pd}-\mathrm{IrOx} / \mathrm{TiO} 2$ : a new insight into dual cocatalyst location, Phys. Chem. Chem. Phys. 16 (2014) 17734-17742. https://doi.org/10.1039/C4CP02567A.

[193] B. Cao, G. Li, H. Li, Hollow sphericalRuO2@TiO2@Pt bifunctional photocatalyst for coupled $\mathrm{H} 2$ production and pollutant degradation, Appl. Catal. B: Environ. 194 (2016) 42-49. https://doi.org/10.1016/j.apcatb.2016.04.033.

[194] M. Zhu, Y. Wang, Y.H. Deng, X. Peng, Strategic modulation of energy transfer in Au-TiO2-Pt nanodumbbells: plasmon-enhanced hydrogen evolution reaction, Nanoscale. 12 (2020) 7035-7044. https://doi.org/10.1039/D0NR00441C.

[195] C. Han, W. Mao, K. Bao, H. Xie, et al., Preparation of $\mathrm{Ag} / \mathrm{Ga} 2 \mathrm{O} 3$ nanofibers via electrospinning and enhanced photocatalytic hydrogen evolution, Int. J. Hydrog. Energy. 42 (2017) 19913-19919. https://doi.org/10.1016/j.ijhydene.2017.06.076.

[196] S.I. Sadovnikov, E.A. Kozlova, E.Yu. Gerasimov, A.A. Rempel, Photocatalytic hydrogen evolution from aqueous solutions on nanostructured Ag2S and Ag2S/Ag, Catal. Commun. 100 (2017) 178-182. https://doi.org/10.1016/j.catcom.2017.07.004.

[197] Q. Jiang, L. Li, J. Bi, S. Liang, M. Liu, Design and Synthesis of TiO2 Hollow Spheres with Spatially Separated Dual Cocatalysts for Efficient Photocatalytic Hydrogen Production, Nanomaterials. 7 (2017) 24. https://doi.org/10.3390/nano7020024.

[198] R. Asai, H. Nemoto, Q. Jia, K. Saito, et al., A visible light responsive rhodium and antimony-codoped $\mathrm{SrTiO} 3$ powdered photocatalyst loaded with an $\mathrm{IrO} 2$ cocatalyst for solar water splitting, Chem. Commun. 50 (2014) 2543-2546. https://doi.org/10.1039/C3CC49279F.

[199] J. Yang, H. Yan, X. Wang, F. Wen, et al., Roles of cocatalysts in Pt-PdS/CdS with exceptionally high quantum efficiency for photocatalytic hydrogen production, J. Catal. 290 (2012) 151-157. https://doi.org/10.1016/j.jcat.2012.03.008.

[200] H. Yan, J. Yang, G. Ma, G. Wu, et al., Visible-light-driven hydrogen production with extremely high quantum efficiency on PtPdS/CdS photocatalyst, J. Catal. 266 (2009) 165-168. https://doi.org/10.1016/j.jcat.2009.06.024.

[201] J. Ding, X. Li, L. Chen, X. Zhang, et al., Au-Pt alloy nanoparticles site-selectively deposited on CaIn2S4 nanosteps as efficient photocatalysts for hydrogen production, J. Mater. Chem. A. 4 (2016) 12630-12637. https://doi.org/10.1039/C6TA04468A.

[202] X. Li, H. Liu, S. Liu, J. Zhang, W. Chen, et al., Effect of Pt-Pd hybrid nano-particle on CdS's activity for water splitting under visible light, Int. Hydrog. Energy. 41 (2016) 23015-23021. https://doi.org/10.1016/j.ijhydene.2016.11.059.

[203] C. Han, L. Wu, L. Ge, Y. Li, Z. Zhao, AuPd bimetallic nanoparticles decorated graphitic carbon nitride for highly efficient reduction of water to $\mathrm{H} 2$ under visible light irradiation, Carbon. 92 (2015) 31-40. https://doi.org/10.1016/j.carbon.2015.02.070.
[204] J. Yang, H. Yan, X. Zong, F. Wen, et al., Roles of cocatalysts in semiconductor-based photocatalytic hydrogen production, Phil. Trans. R. Soc. A. 371 (2013) 20110430 https://doi.org/10.1098/rsta.2011.0430.

[205] S. Shen, L. Guo, X. Chen, F. Ren, S.S. Mao, Effect of Ag2S on solar-driven photocatalytic hydrogen evolution of nanostructured CdS, Int. J. Hydrog. Energy. 35 (2010) 7110-7115. https://doi.org/10.1016/j.ijhydene.2010.02.013.

[206] G. Sun, S. Mao, D. Ma, Y. Zou, et al., One-step vulcanization of $\mathrm{Cd}(\mathrm{OH}) \mathrm{Cl}$ nanorods to synthesize $\mathrm{CdS} / \mathrm{ZnS} / \mathrm{PdS}$ nanotubes for highly efficient photocatalytic hydrogen evolution, J. Mater. Chem. A. 7 (2019) 15278-15287. https://doi.org/10.1039/C9TA03862K.

[207] I. Tsuji, H. Kato, A. Kudo, Photocatalytic Hydrogen Evolution on $\mathrm{ZnS}-\mathrm{CuInS} 2-\mathrm{AgInS} 2$ Solid Solution Photocatalysts with Wide Visible Light Absorption Bands, Chem. Mater. 18 (2006) 1969-1975. https://doi.org/10.1021/cm0527017.

[208] J.S. Jang, D.W. Hwang, J.S. Lee, CdS-AgGaS2 photocatalytic diodes for hydrogen production from aqueous $\mathrm{Na} 2 \mathrm{~S} / \mathrm{Na} 2 \mathrm{SO} 3$ electrolyte solution under visible light $(\lambda \geq 420 \mathrm{~nm})$, Catal. Today. 120 (2007) 174-181. https://doi.org/10.1016/j.cattod.2006.07.052.

[209] X. Huang, Y. Huang, F. Yan, X. Xue, et al., Constructing defect-related subband in silver indium sulfide QDs via $\mathrm{pH}-$ dependent oriented aggregation for boosting photocatalytic hydrogen evolution, J. Colloid Interface Sci. 593 (2021) 222-230. https://doi.org/10.1016/j.jcis.2021.02.091.

[210] Y. Shiga, N. Umezawa, N. Srinivasan, S. Koyasu, et al., A metal sulfide photocatalyst composed of ubiquitous elements for solar hydrogen production, Chem. Commun. 52 (2016) 7470-7473. https://doi.org/10.1039/C6CC03199D.

[211] S. Chandrasekaran, L. Yao, L. Deng, C. Bowen, et al., Recent advances in metal sulfides: from controlled fabrication to electrocatalytic, photocatalytic and photoelectrochemical water splitting and beyond, Chem. Soc. Rev. 48 (2019) 4178-4280. https://doi.org/10.1039/C8CS00664D.

[212] S. Zhu, Y. Zhang, X. Qian, X. Wang, W. Su, Zn defectmediated Z-scheme electron-hole separation in AgIn5S8/ZnS heterojunction for enhanced visible-light photocatalytic hydrogen evolution, Appl. Surf. Sci. 504 (2020) 144396. https://doi.org/10.1016/j.apsusc.2019.144396.

[213] Y. Liu, X. Zheng, Y. Yang, J. Li, et al., Photocatalytic Hydrogen Evolution Using Ternary-Metal-Sulfide/TiO2 Heterojunction Photocatalysts, ChemCatChem. (2021). https://doi.org/10.1002/cctc.202101439.

[214] H. Wu, X. Li, Y. Cheng, Y. Xiao, et al., The synergistic role of double vacancies within AgGaS2 nanocrystals in carrier separation and transfer for efficient photocatalytic hydrogen evolution, Catal. Sci. Technol. 9 (2019) 5838-5844. https://doi.org/10.1039/C9CY01488H.

[215] J.S. Jang, S.J. Hong, J.Y. Kim, J.S. Lee, Heterojunction photocatalyst $\mathrm{TiO} 2 / \mathrm{AgGaS} 2$ for hydrogen production from water under visible light, Chem. Phys. Lett. 475 (2009) 78-81. https://doi.org/10.1016/j.cplett.2009.05.012.

[216] J.S. Jang, D.W. Hwang, J.S. Lee, CdS-AgGaS2 photocatalytic diodes for hydrogen production from aqueous $\mathrm{Na} 2 \mathrm{~S} / \mathrm{Na} 2 \mathrm{SO} 3$ electrolyte solution under visible light $(\lambda \geq 420 \mathrm{~nm})$, Catal. Today. 120 (2007) 174-181. https://doi.org/10.1016/j.cattod.2006.07.052.

[217] F. Cao, H. Liu, Q. Wei, L. Zhao, L. Guo, Experimental study of direct solar photocatalytic water splitting for hydrogen production under natural circulation conditions, Int. J. Hydrog. Energy. 43 (2018) 13727-13737. https://doi.org/10.1016/j.ijhydene.2017.12.107.

[218] I. Salahshoori, A. Seyfaee, A. Babapoor, Recent advances in synthesis and applications of mixed matrix membranes, Synth. Sinter. 1 (2021) 1-27. https://doi.org/10.53063/synsint.2021.116. 